Published in final edited form as:

Front Biosci (Landmark Ed). ; 20: 37-77.

\title{
The role of microRNAs in skeletal muscle health and disease
}

\author{
Tyler J. Kirby ${ }^{1,2}$, Thomas Chaillou ${ }^{1,2}$, and John J. McCarthy ${ }^{1,2}$ \\ ${ }^{1}$ Center for Muscle Biology, University of Kentucky, Lexington, KY, USA \\ ${ }^{2}$ Department of Physiology, College of Medicine, University of Kentucky, Lexington, KY, USA
}

\begin{abstract}
Over the last decade non-coding RNAs have emerged as importance regulators of gene expression. In particular, microRNAs are a class of small RNAs of $\sim 22$ nucleotides that repress gene expression through a post-transcriptional mechanism. MicroRNAs have been shown to be involved in a broader range of biological processes, both physiological and pathological, including myogenesis, adaptation to exercise and various myopathies. The purpose of this review is to provide a comprehensive summary of what is currently known about the role of microRNAs in skeletal muscle health and disease.
\end{abstract}

\section{Keywords}

MyomiR; Exercise; Hypertrophy; Atrophy; Muscular dystrophy; Review

\section{INTRODUCTION}

\subsection{History}

Initially described as a small RNA involved in developmental timing, the study of the first microRNA (miRNA) lin-4 was carried out in relative obscurity in the early 1990s, of real interest to only those in the nematode (Caenorhabditis elegans) community $(1,2)$. These pioneering studies by the Ruvkun and Ambros laboratories provided the first evidence demonstrating that lin-14 expression was regulated by a post-transcriptional mechanism involving the interaction between the lin-143'-UTR and the small non-coding RNA lin-4 $(3,4)$. Pasquinelli and colleagues reported in late 2000 the identification of let-7, a second "small temporal RNA" (stRNA) from C. elegans that down-regulated lin-41 expression, and unlike lin-4, was detected in a broad range of bilaterian animals including vertebrate, ascidian, hemichordate, mollusc, annelid and arthropod (5). The discovery that let-7 was phylogenetically conserved in bilaterian animals was a major milestone in the history of the miRNA field as it strongly suggested the post-transcriptional regulation of gene expression by small RNAs was more wide-spread than just $C$. elegans. Shortly thereafter, three independent reports described the identification of 30-50 new miRNAs in the human, fly and worm, providing additional support for the idea that miRNAs may have an important role in the regulation of gene expression in animals (6-9). The prescient nature of these early

Send correspondence to: John J. McCarthy, University of Kentucky, Department of Physiology, 800 Rose Street, MS508, Lexington, KY 40536-0298, Tel: 859-323-4730, Fax: 859-323-1070, jjmcca2@email.uky.edu. 
findings is revealed in the latest release of miRBase (version 20, June, 2013;

www.mirbase.org) which catalogs 30,424 miRNA sequences from 206 species with 2578

and 1908 human and mouse miRNAs, respectively.

\subsection{Biogenesis}

The vast majority of miRNAs are the product of RNA polymerase II transcription resulting in a primary miRNA (pri-miRNA) transcript that has the characteristic $5^{\prime} \mathrm{m}^{7} \mathrm{G}$ cap structure and $3^{\prime}$ poly(A) tail $(10,11)$. Recent genomic mapping confirmed an earlier study showing that roughly half of annotated miRNAs are intragenic (exon, intron, $3^{\prime}$-UTR or $5^{\prime}$-UTR), located within protein-coding or non-coding RNA (ncRNA) genes $(12,13)$. In general, miRNA expression parallels the host gene, though new experimental evidence indicates that up 30\% of intronic miRNAs are expressed as an independent transcription unit under regulation of its own promoter (14). Once transcribed, the pri-miRNA forms a stem-loop structure that is recognized by the microprocessor complex which contains two core components, the RNase III endonuclease Drosha and the double-stranded RNA binding protein DGCR8 (Di George Syndrome critical region gene 8) (15, 16). DGCR8 binds to the stem-loop structure and then guides Drosha into position, cleaving 11 base pairs (bp) from the base of the stem-loop to produce a 60-70 bp hairpin RNA molecule designated the precursor miRNA (pre-miRNA) (17). The generation of certain pre-miRNAs have been shown to be regulated by proteins that are not core components of the microprocessor complex (18). For example, SMAD interacts with p68, a RNA helicase associated with the microprocessor complex, to promote production of miR-21 which is known to regulate AKT activity by targeting PTEN (phosphotase and tensin homolog) (19, 20). Given the importance of TGF- $\beta$ (transforming growth factor- $\beta$ ) signaling in the regulation of skeletal muscle mass, it would be of interest to see if such a similar mechanism is operative during periods of muscle growth.

Following pri-miRNA processing, the $60-70$ bp precursor miRNA (pre-miRNA) is transported from the nucleus by Exportin 5, a nuclear export receptor, to the cytoplasm (21, 22). Once in the cytoplasm, a second RNase III endonuclease, Dicer, cleaves the pre-miRNA to produce $\sim 22$ nucleotide double-stranded RNA molecule in which one strand, known as the guide strand, is transferred to RISC (RNA-induced silencing complex) containing Argonaute 2 (Ago2) and the RNA binding protein Tarbp2 (TAR (HIV) RNA binding protein 2 ); the other strand is typically targeted for degradation (23). The mature miRNA directs RISC to 3'-UTR of target mRNA through complementary binding of the miRNA seed sequence which results in inhibition of translation and/or degradation of the target transcript (24). As with Drosha, Dicer activity has been shown to be modified by its association with different factors (25). In particular, the cold-shock protein RBM3 (RNA binding motif protein 3) has been shown to promote pre-miRNA association with Dicer leading to an increase in mature miRNA expression; interestingly, Dupont-Versteegden and coworkers reported RBM3 appears to be capable of regulating muscle size $(26,27)$.

Although the vast majority of miRNAs are generated through the aforementioned pathway, there are examples of miRNAs being produced independent of Drosha and Dicer $(28,29)$. Cheloufi and colleagues made the unexpected discovery that miR-451 could be generated 
through the processing of pre-miRNA-451 by Ago2 (30). Interestingly, expression of miR-451 has been reported to decrease with age in skeletal muscle and be increased during differentiation of human myoblasts as well as in low responders to resistance exercise (31, 32). What remains to be reconciled with these intriguing findings is the observation, using a mouse $\beta$-galactosidase reporter strain, that miR-451 expression is restricted to the circulatory system, consistent with miR-451 known role in erythropoiesis (33). Though speculative, it may be that some of the findings reported for miR-451 in skeletal muscle reflect concomitant changes in the vascular system and not the muscle itself per se.

\subsection{Tissue-specific expression}

Almost immediately upon discovering that miRNAs were conserved across species, came the realization that some miRNAs were not ubiquitously expressed as let-7, but were expressed only in certain tissues. One of the first examples of a tissue-specific miRNA was miR-1 which was found to be expressed exclusively in the human heart but not in the brain, kidney, liver, lung or HeLa cells $(6,8)$. The initial finding that some miRNAs were expressed in a tissue-specific fashion was confirmed in a study by Lagos-Quintana and coworkers (2002) showing that miR-1, $-122 \mathrm{a}$ and $-124 \mathrm{a}$ expression was restricted to striated muscle, liver and brain, respectively (9). In an effort to identify new miRNAs, Sempere et al. (2004) identified 30 miRNAs that were enriched or specifically expressed within a particular tissue (34). These authors provided the first description of striated muscle-specific miR-1, $-133 \mathrm{a}$ and -206 , which were later designated as myomiRs $(34,35)$.

The myomiR family has expanded since its original description to include miR-208a, miR-208b, miR-499 and, most recently, miR-486 (36-38). Northern blot analyses showed that these new members of the myomiR family are strictly striated muscle-specific (miR-208a, miR-208b and miR-499), being derived from the intron of different musclespecific myosin heavy chain genes, or highly enriched in muscle (miR-486) $(36,37)$. Most myomiR family members are expressed in both the heart and skeletal muscle except for miR-208a, which is cardiac-specific, and miR-206, which is skeletal muscle-specific and enriched in slow-twitch muscles such as the soleus (39).

\subsection{MyomiRs}

Since their original description, a great of effort has gone into determining the function of myomiRs in striated muscle (reviewed in Liu and Olson, 2010) (40). The finding that overexpression of miR-1 was capable of promoting a shift to a myogenic profile in HeLa cells indicated that myomiRs may have a fundamental role in muscle biology (41). The importance of myomiRs in the regulation of myogenesis was first demonstrated by Sokol and Ambros (2005) who reported the deletion of miR-1 in the fly resulted in premature death resulting from incomplete skeletal muscle growth during early development (42). Interestingly, myomiRs appear to have either uniform expression throughout the muscle (miR-1 and miR-133a), independent of fiber-type, or are enriched in slow-twitch, type I muscles (miR-206, miR-208b and miR-499) $(37,39)$; to date, no myomiR has been reported to be enriched specifically in fast-twitch, type II muscle. However, RNA-seq analysis of porcine and bovine skeletal muscle has identified non-myomiRs that are relatively enriched in a muscle of a particular fiber type $(43,44)$. For instance, Muroya and colleagues (2013) 
reported that in steers miR-885 and miR-196a were highly enriched in the fast-twitch semitendinosus muscle relative to the slow-twitch masseter muscle (44).

Gene targeting studies have shown that deletion of individual myomiRs in the mouse has had surprisingly little impact on skeletal muscle phenotype $(37,38,45-49)$. For example, deletion of skeletal muscle-specific miR-206 resulted in no obvious phenotype as reflected by soleus muscle weight, morphology or fiber-type distribution; however, recovery from denervation was delayed in muscle of the miR-206 knockout (47). In a similar manner, the Olson laboratory showed that miR-208a was necessary for the stress response involved in cardiac hypertrophy (38). Collectively, these findings from myomiR knockout mice are consistent with the notion that a primary function of miRNAs is to mediate the stress response of the cell by helping to restore homeostasis through regulating gene expression (50); however, why the myomiR knockout mice do not show a more dramatic phenotype as predicted from in vitro studies remain unclear $(51,52)$. One possible explanation could be the overlap in target genes among myomiR family members, such as miR-1 and miR-206, which in theory could rescue any deleterious phenotype resulting from the miRNA knockout. This idea is supported by the double knockout of miR-133a-1 and miR-133a-2 in which mice showed septal defects and skeletal muscle myopathy that was not present in the single miR-133a knockout mice $(53,54)$.

The purpose of this review is to, first, present the current knowledge about the role of miRNAs during skeletal muscle formation and regeneration, as well as in response to muscular activity. Secondly, the review will summarize the functions of miRNAs in skeletal muscle disorders, including dystrophies and myopathies, disorders related to disease and disuse, and sarcopenia.

\section{MICRORNA REGULATION OF MYOGENESIS}

It is now well-established that miRNAs play an integral role in skeletal muscle development, particularly through their regulation of myogenic progenitor cells. Myogenesis is an extremely complex biological process that is beyond the scope of this review; for a comprehensive overview of myogenesis, the reader is kindly referred to these in-depth reviews (55-58). Briefly, during skeletal muscle development, two upstream regulatory factors, $\operatorname{Pax} 3$ (paired box 3) and $\operatorname{Pax} 7$ (paired box 7), are expressed in progenitor cells during the determination and formation of skeletal muscle (for recent reviews see 58). Furthermore, the fate of these cells is controlled by a complex network of basic helix-loophelix muscle regulatory factors (MRFs) which include MYOD (myogenic differentiation), MYF5 (myogenic factor 5), myogenin, and MRF4 (myogenic regulatory factor 4) (for comprehensive reviews see 58-61), and it is primarily through the regulation of these transcription factors that miRNAs exert their biological effect in skeletal muscle.

Additionally, Mef2 (Myocyte enhancer factor 2) transcription factors are also important during muscle differentiation (for review see 62), and have been shown to be regulated by miRNAs (63-66).

To date, most of the work that has contributed to our understanding of miRNAs during myogenesis has been performed using the myogenic $\mathrm{C} 2 \mathrm{C} 12$ cell line. This cell line readily 
recapitulates the proliferation and differentiation processes that myogenic progenitor cells undergo during formation of skeletal muscle in vivo. However, following post-natal development, myogenic cells transition into a state of quiescence, which is difficult to study using an in vitro model. Due to these limitations, only recently have reports emerged implicating miRNAs during the transition and maintenance of myogenic cells into this state of quiescence $(67,68)$. During this post-natal period, these cells specifically express the transcription factor $\operatorname{Pax} 7$ and are referred to as satellite cells (61). Furthermore, while these cells normally remaining quiescent, upon injury, satellite cells become activated, enter the cell cycle, and proliferate, serving as the cellular basis for muscle repair. Therefore, miRNAs play a role not only in the development of skeletal muscle, but also during regeneration following muscle injury, a process that recapitulates the different stages of myogenesis. The miRNAs and their respective targets that have been experimentally-shown to regulate myogenesis are listed in Table 1. Moreover, a summary of our current understanding of the major miRNAs involved in the regulation of myogenesis is shown in Figure 1.

\subsection{Proliferation}

The early work by Chen and colleagues (2006) was one of the first to provide evidence indicating that miRNAs regulate the proliferative behavior of myogenic cells (52). These authors reported that over-expression of miR-133a promoted myoblast proliferation by repressing the expression of $\operatorname{Srf}$ (serum response factor) (52). Similarly, miR-27a has since been shown to be involved in promoting myoblast proliferation by targeting a well-known negative regulator of myogenesis, myostatin (69). The regulation of cell proliferation through myostatin appears to be through an auto-regulatory loop involving the myostatin downstream target Smad3/4 complex; activation of the Smad3/4 complex, in turn, leads to miR-27a induction which then feeds back to inhibit myostatin expression (70). Microarray analysis of proliferating myogenic cells revealed that miR-682 is up-regulated, with functional assays demonstrating that inhibition of miR-682 is capable of attenuating proliferative response, though no definitive target genes underlying this response were identified (71). It should be noted, however, that miR-682 is only present in murine animals, possibly precluding a similar role in human myogenesis.

\subsection{Differentiation}

Relative to the limited number of studies investigating the function of miRNAs in myoblast proliferation, the role of miRNAs in regulating myogenic differentiation has been more fully explored. As would be expected, the initial studies focused on those miRNAs that are enriched in skeletal muscle, the myomiRs. Chen and colleagues (2006) demonstrated that miR-1 promoted differentiation by relieving chromatin-based repression of the myogenic regulatory factors through regulation of Hdac4 (histone deacetylase 4) expression (52). The same group went on to show that miR-1 and -206 restrict myogenic progenitor cell proliferation and promote differentiation by directly regulating expression of $\operatorname{Pax} 7$ (72). The regulation of $\operatorname{Pax} 7$ expression by miR-206 was more recently confirmed by Dey and coworkers, who further demonstrated that $\operatorname{Pax} 7$ expression was also subject to regulation by miR-486 (73). Another mechanism through which miR-206 promotes myogenic differentiation is by inducing myoblast to exit the cell cycle through repression of specific subunits of DNA polymerase a as well as by targeting $\operatorname{Hdac} 4(51,74)$. Similarly, miR-1 has 
been shown to regulate cell cycle progression by targeting Cyclin D1, thereby promoting G1 cell cycle arrest (75). During myoblast fusion, both miR-1 and -206 have been shown to inhibit the translation of Gjal (gap junction protein, alpha 1)/Connexin 43 in order to block the formation of gap junctions (76). Although Connexin43 expression is necessary for myoblast fusion and muscle regeneration, its down-regulation is required for myotube survival $(77,78)$. Furthermore, it is likely that miR-1 and miR-206 regulate many other genes involved in the differentiation process, as manipulation of their levels during differentiation results in significant alterations in the transcriptome of $\mathrm{C} 2 \mathrm{C} 12$ cells (79).

The role of miR-133 during myogenic differentiation appears to be more complex than miR-1/206. Early reports indicated that miR-133 possessed pro-proliferative properties through the regulation of Srf expression (52); however recent studies are challenging these findings, suggesting that miR-133 promotes differentiation similar to miR-1 and miR-206 $(75,80)$. Although these latest findings seem to be biologically more consistent (i.e., serving a similar function), given that miR-1 and miR-133 are derived from the same pri-miRNA transcript, Zhang et al., (2012) showed that miR-133, through p38-mediated signaling, inhibited proliferation by directly targeting the transcription factor $S p 1$ (trans-acting transcription factor 1), which in turn activates Cyclin D1 expression $(75,81)$. Similarly, a more recent study demonstrated that miR-133 promoted differentiation by down-regulating two members of the ERK1/2 signaling pathway, FGFR1 (fibroblast growth factor receptor 1) and PP2AC (protein phosphatase 2, catalytic subunit, alpha isozyme), which the authors showed were part of a pro-proliferation signaling cascade (80).

In addition to the muscle-enriched miRNAs, other miRNAs have been implicated in potentially playing a role in myogenic differentiation. Wong and coworkers (2008) showed that endogenous levels of miR-26a increased during myogenic differentiation and that overexpression of this miR-26a promoted the myogenic program (82). These authors reported that miR-26a regulated the expression of Ezh2 (enhancer of zeste homolog 2), a catalytic subunit of the polycomb repressive complex, thereby relieving the repressive histone modifications on multiple myogenic genes (82). MiR-26a has also been shown to downregulate TGF- $\beta$ signaling, a well-established inhibitor of myogenesis, by targeting two downstream effector genes of the pathway, Smad1 and Smad4 (83). Similarly, MyoD and myogenin are able to drive expression of miR-214, which also targets Ezh2, providing a feedback loop to promote the expression of genes required for differentiation (84). In addition, miR-214 can also promote myoblast cell cycle exit by repressing the protooncogene gene $N$-ras (neuroblastoma ras oncogene) expression along with potentially playing a role in specifying myogenic lineage $(85,86)$. MiR-322/424 and -503 have also been shown to promote cell cycle exit of myoblasts through the down-regulation of $C d c 25 \mathrm{~A}$ (cell division cycle 25A), the phosphatase responsible for removing the inhibitory phosphorylation on T14 and Y15 of CDK2 (cyclin-dependent kinase 2) (87).

$\mathrm{MiR}-29 \mathrm{~b} / \mathrm{c}$ is another non-muscle-specific microRNA that appears to play an important role in regulation of myogenesis $(55,74,88-92)$. MiR-29 b/c was first identified as a potential factor involved in myogenesis through the identification of upstream binding sites for the Polycomb group protein, YY1 (yin yang 1) (88). YY1 is a downstream target of the NFkB (nuclear factor kappa B) signaling pathway that functions to inhibit myogenesis through 
repression of myogenic gene expression. Interestingly, YY1 itself is a target of miR-29 which provides a feedback loop in which increased expression of miR-29 serves to relieve the repressive effects of YY1 and promote myogenesis (88). It was later shown that miR-29 also targets another gene in this pathway, Rybp (Ring 1 and YY1-binding protein), which the authors demonstrate co-occupies myogenic loci along with YY1 (91). Therefore, it appears that a primary function of miR-29 is to promote myogenesis by down-regulating multiple targets in the NFkB signaling pathway. In addition to genes within the NFkB pathway, miR-29 also regulates the expression of $\mathrm{Hdac} 4$ and $A k t 3$ to promote myogenic differentiation $(74,90)$. Not only does it appear that miR-29 is responsible for promoting myogenesis, but it may also play a role in preventing myoblasts from adopting an alternate cell fate (92). The canonical TGF- $\beta /$ Smad signaling pathway, a well-known pathway involved in fibrosis formation, appears to negatively regulate the expression of miR-29 thereby promoting the conversion of myoblasts in myofibroblasts (92). In support of the potential involvement of miR-29 in development of fibrosis, Wang and colleagues (2012) demonstrated that the loss of miR-29 may play a role in the development of a dystrophic phenotype (55).

MiR-181 has been shown to promote myogenic differentiation by targeting Hoxa11 (homeobox A11), a negative regulator of $M y o D$ expression (93, 94). Inhibition of miR-181 decreased differentiation of $\mathrm{C} 2 \mathrm{C} 12$ myoblasts; however, over-expression of miR-181 was not capable of inducing myogenic differentiation, leading the authors to conclude that miR-181 is necessary, but not sufficient, for myogenic differentiation (93). Recently, two novel microRNAs, miR-675-3p and miR-675-5p were identified within an exon of an imprinted long noncoding RNA, H19 (95). While H19 is normally not expressed in adult tissue, the authors eloquently demonstrated that not only is H19 expressed in skeletal muscle, but these two miRNAs are able to promote myogenic differentiation through the down-regulation of multiple factors, including Smad1, Smad5 and Cdc6 (cell division cycle 6) (95).

The Mef2 isoforms are transcription factors that act in conjunction with MRFs to regulate muscle differentiation (58). One aspect of Mef2 regulation of myogenesis is through the control of the tissue-specific expression of the bicistronic precursor RNA encoding miR-1-2 and 133a-1 (81). In addition, Mef2a was recently reported to control the expression of a large number of miRNAs located in the Gt12-Dio3 locus through the regulation of an upstream promoter (96). In vitro, miR-155 has been shown to repress Mef2a expression thereby blocking myogenic differentiation (66). The Mef2c isoform was shown to be targeted by miR-27b, which is consistent with the idea that miR-27 promotes the proliferative state of myogenic cells $(70,97)$. Furthermore, through the regulation of $\operatorname{Pax} 3$, over-expression of miR-27b using a conditional transgene resulted in abnormal migration of Pax3+ progenitor cells along with premature differentiation (98). Recently a cardiac- and muscle-specific miRNA, miR-92b, was identified in Drosophila and found to be required for normal muscle development through its regulation of Mef2 (63). In addition, the canonical myomiRs miR-1 and -206 were reported to indirectly regulate Mef2c through repression of Notch 3 expression, which under normal conditions antagonizes Mef $2 c$ expression to inhibit myogenic differentiation (64). 
Finally, upon differentiation, myofibers begin to express contractile proteins, including multiple myosin heavy chain isoforms. Recently, miR-23a was shown to inhibit myogenic differentiation by targeting multiple adult fast myosin heavy chain genes, including Myh 1, 2 and 4 (99). In addition, muscle cells contain a highly structured cytoskeleton, with assembly of the cytoskeleton governed primarily through RhoA (ras homolog family member A) signaling (100). ROCK1 (Rho-associated, coiled-coil containing protein kinase 1) is a downstream target of RhoA, which acts to stabilize actin, and whose expression is required to be down-regulated to allow for terminal myoblast differentiation presumably to allow for cytoskeleton remodeling during myoblast fusions $(101,102)$. The down-regulation of Rock1 expression is partially controlled by miR-148a targeting; accordingly, inhibition of miR-148a activity by an antagomir impairs myogenic differentiation (103). Therefore, miRNAs not only control myogenic differentiation through the regulation of transcription factors but also through the direct regulation of structural proteins and cytoskeletal components that are required to give rise to the differentiated phenotype.

\subsection{Quiescence}

In vivo, myogenic stem cells or satellite cells are normally in a quiescent state following post-natal development. This makes studying their behavior difficult, and precludes the use of in vitro models to study the role of miRNAs in the regulation of this quiescent state. Only recently has evidence emerged demonstrating that miRNAs are involved in maintaining quiescence in satellite cells $(67,68,104)$. Using the conditional inactivation of Dicer in satellite cells, Cheung and coworkers showed that mature miRNAs were required to maintain satellite cell quiescence, as satellite cells that lacked a functional Dicer gene spontaneously exited the quiescent state (67). These same authors went on to demonstrate that miR-489 is a key miRNA involved in satellite cell quiescence due to its regulation of the proto-oncogene Dek, which normally acts to promote the proliferative expansion of myogenic progenitors (67). Another miRNA, miR-31, was found to regulate the expression of the myogenic regulatory factor Myf5 in quiescent satellite cells (68). Crist and coworkers (2012) reported that miR-31 and Myf5 are held in close proximity to one another as part of messenger ribonucleoprotein particles (mRNPs) (68). Upon satellite cell activation, these mRNPs rapidly dissociate and relieve the spatial constraint on miR-31 and Myf5, allowing for the rapid translation of the Myf5 protein (68). Furthermore, miRNA expression profiling of isolated quiescent satellite cells, revealed that additional miRNAs are down-regulated in comparison to proliferating and differentiating cells (104). These finding suggest that perhaps there are other miRNA required to maintain the quiescent state of satellite cells; however, whether the involvement of these miRNAs is direct or indirect, as well as their target genes, remains to be elucidated.

\section{MANIPULATION OF MICRORNA EXPRESSION ON DE NOVO SKELETAL MUSCLE FORMATION}

\subsection{Development}

Results from in vitro studies have greatly enhanced our understanding of the potential role that miRNAs have in myogenesis in vivo, though the biological significance in the context 
of a whole organism will undoubtedly be more complex. For example, mice that are null for individual muscle-specific miRNAs show no obvious skeletal muscle phenotype $(37,38,45-$ 49). The lack of a phenotype in these different miRNA null mice may in part reflect overlap in their seed sequences, as is the case with miR-1 and -206 , or that individual genes may contain targets for multiple miRNAs. Regardless, it is clear that miRNAs are absolutely required for proper embryonic development, as germline Dicer knockout mice die in utero at day E7.5. (105). Furthermore, a more targeted approach has demonstrated that miRNAs are required for skeletal muscle development, as mice that have Dicer deleted specifically in skeletal muscle die perinatally and exhibit decreased muscle mass and abnormal myofiber morphology (106). The decrease in Dicer-/- muscle mass is first notable at E14.5 and becomes drastically reduced at E18.5. This loss in muscle mass is the result of hypoplasia and not hypotrophy; despite having less mass, there does not appear to be a change in fibertype (106). Though somewhat speculative, this phenotype might reflect the loss of miR-1 expression, which in Drosophila has been shown to be necessary for skeletal muscle development and viability $(42,106)$. The importance of miR-1 in development was further illustrated by Chen and colleagues (2006), who introduced either miR-1 or miR-133 into Xenopus laevis embryo (52). The misexpression of either miR-1 or -133 affected cardiac and skeletal muscle formation, however miR-1 demonstrated a much more dramatic phenotype, with no development of cardiac tissue and highly disorganized somites (52). Surprisingly, either the loss of miR-133a-1 or miR-133a-2 or the over-expression of miR-133a1-2 in mice results in no overt skeletal muscle phenotype $(53,108)$. In contrast, the double-knockout of both miR-133a-1and -133a-2 caused lethal septal defects in approximately $50 \%$ of the offspring with those surviving to adulthood developing dilated cardiomyopathy (53).

\subsection{Regeneration}

One of the defining aspects of skeletal muscle is the capacity to mount a robust regenerative response following extensive injury. Due to this ability to regenerate so effectively, another technique commonly employed to study the role of miRNAs on muscle formation is through the use of an in vivo injury model. The reparative process requires muscle satellite cells to become activated, proliferate and then differentiate such that perturbation of miRNA levels during this process can provide a readout for their function in the context of a whole organism. Studies using regeneration as a model of myogenesis are critical for furthering our knowledge of miRNAs in skeletal muscle biology, as the complexity of factors that exist in vivo more than likely have a dramatic impact on the expression and function of numerous miRNAs. Various studies have provided evidence that muscle injury results in the altered expression of numerous miRNAs $(93,109)$, though a few studies have performed gain- and loss-of-function experiments to characterize the functional outcome with regards to regenerative capabilities $(83,98,110)$. Crist and colleagues (2009) showed that inhibition of miR-27 delayed muscle regeneration by repressing Pax3 expression in satellite cells (98). Conversely, Nakasa et al. (2010) reported enhanced muscle regeneration following a laceration injury by injection of exogenous myomiRs miR-1, -133 and -206 (111). These authors showed that this myomiR concoction caused increased expression of $M y O D$, myogenin and $\operatorname{Pax} 7$ while concomitantly decreasing expression of myostatin (111). Another study confirmed the regulation of $\mathrm{Pax} 7$ expression and satellite cell proliferation by miR-1 
and -206 during muscle regeneration, though the authors did not investigate the effect of this regulation on the regeneration process (72). A later report did however demonstrate that loss of miR-206 expression exacerbated injury-induced regeneration through defective differentiation of satellite cells, mostly likely due to the inability to down-regulate $\operatorname{Pax} 7$ expression (46). Furthermore, miR-206 has been recently shown to target the $\mathrm{Hmgb3}$ (High Mobility Group Box 3) gene during regeneration (112), which is known to be involved in stem cell self-renewal and differentiation (113). Collectively, the results from these studies indicated that miR-1 and -206 are required for skeletal muscle regeneration, with a primary function to insure the proper down-regulation of genes involved in the differentiation process of satellite cells.

MiRNAs other than myomiRs have been shown to regulate satellite cell proliferation and differentiation by altering TGF- $\beta$ signaling pathway. MiR-26a expression is rapidly downregulated following muscle injury but then slowly increases a few days following the injury (83). Dey and colleagues (2012) demonstrated that miR-26a is required to suppress TGF- $\beta$ signaling during differentiation through the regulation of SMAD1 and 4, whereas muscles with reduced miR-26a levels showed a delayed regenerative response (83). This same group recently identified two additional novel miRNAs, miR-675-3p and miR-675-5p, which are derived from the $\mathrm{H} 19$ long non-coding RNA and are required for proper muscle regeneration through by inhibiting TGF- $\beta$ signaling (95). Restricting TGF- $\beta$ signaling further promotes myogenic differentiation by permitting an increase in the expression of the prodifferentiation miRNAs, miR-29 and -206 (74). Together, the findings of these studies confirm the numerous in vitro studies examining the central role that miRNAs have in the regulation of myogenic differentiation.

Recently, the well-studied mTOR (mechanical target of rapamycin) pathway has been implicated during skeletal muscle regeneration, as inhibition of this pathway impairs injuryinduced regeneration (114). One mechanism through which mTOR is thought to regulate regeneration is by affecting the expression of Igf-II (insulin-like growth factor II) (114). Part of this regulation appears to involve miR-125b, which has been shown to be negatively regulated by mTOR (110). Therefore, miR-125b acts as a negative regulator of muscle regeneration through its suppression of Igf-II expression, and furthermore, decreasing miR-125b levels during regeneration ameliorated this process (110). In addition, mTOR activation also increases the expression of miR-1 which then controls satellite cell activity as previously outlined (115). AKT/IRS1 (insulin receptor substrate-1) signaling lies upstream of the mTOR complex and is involved in regeneration. Recently, Alexander and colleagues (2011) demonstrated that during regeneration AKT signaling is regulated by miR-486 (116). Normally, miR-486 is induced during regeneration allowing for activation of AKT1 through the down-regulation of PTEN (116), a well-characterized negative regulator of AKT signaling. Inappropriate over-expression of miR-486 resulted in abnormal regeneration, presumably through the misregulation of many target genes (116). Another miRNA, miR-199a-3p, was recently shown to regulate multiple targets within the AKT/mTOR signaling pathway in vitro; however, the importance of miR-199a-3p in the regulation of skeletal muscle regeneration remains unknown (117). These findings indicate that components of the AKT/mTOR signaling pathway are subject to regulation by both musclespecific and non-muscle-specific miRNAs. 
While de novo muscle formation occurs both during development and following regeneration, it appears that these processes may have some distinct features with respect of their requirement for microRNA regulation. For example, miR-206 is required for effective regeneration to occur (46), however is dispensable for proper development (47). One explanation for these discrepancies may result from differences in the state of the myogenic progenitor pools that give rise to each of these processes. Furthermore, expression of additional microRNAs may result in a compensatory mechanism during development, however their expression may be absent in adult muscle. Future research will no doubt reveal additional miRNA or gene targets involved in this regulation of myogenesis, both during development and adulthood, thereby adding further complexity to an already intricate biological process. Moving forward, future gain-and loss-of-function studies need to consider the temporal expression of microRNAs during muscle formation, as inappropriate timing of expression could results in an extremely different phenotype. These intricacies will need to well defined if there is ever a hope to use this system for potential therapeutic benefit. Moreover, emerging evidence is indicating that microRNAs may play a role during normal muscle maintenance during adulthood, along with potentially modulating muscle adaptation.

\subsection{Innervation}

The functionality of skeletal muscle requires innervation by the central nervous system in order to form muscle motor units. Dysfunctional or loss of innervation results in multiple muscular disorders, as will be discussed in later sections. Therefore, the formation and maintenance of the neuromuscular junction (NMJ) is a critical step in the formation of mature skeletal muscle, of which microRNAs have shown to perform an integral role. Specifically, it appears that microRNAs play a role in synapse formation $(118,119)$, NMJ sensitivity (120-122), and reinnervation following injury (47, 123). During development in Drosophila, let-7 and miR-125 control the maturation of the NMJ through targeting of the abrupt gene $(118,119)$, .Originally described in $C$. elegans, miR-1 directly regulates the expression acetylcholine (Ach) receptor subunits, along with pre-synaptic ACh release in a MEF-2-dependent mechanism (120). These findings suggest that miR-1 is involved in regulation ACh sensitivity within the NMJ. MicroRNA regulation of neurotransmitter release has also been described in Drosophila melanogaster, where the miR-310 cluster negatively regulated synaptic function by targeting $K h c-73$, a kinesin gene required for normal synaptic function (122). Similarly, miR-124 mutants demonstrate aberrant NMJ activity, with miR-124 serving to limit synaptic activity (121). Furthermore, miR-8 negatively regulates the expansion if pre-synaptic terminals (124), both through the regulation of Ena (Enabled) (125) and Wg (wingless) (126). In mammals, miR-206, but not miR-133b, is required for reinnervation of muscle fibers following injury $(47,123)$. Recently, miR-206 was shown to regulate $B d n f$ (brain-derived neurotrophic factor), a factor known to be involved in regulation of innervating motor neurons, in differentiating myoblasts (127). However, it remains to be determined whether this regulation is important for the reinnervation process. Further research is required to identify additional targets of miR-206 within the NMJ in order to elucidate the underlying mechanism by which miR-206 controls reinnervation. Collectively, these findings suggest a critical role for microRNAs during NMJ formation, with further research required to whether they play a role in 
regulating the maintenance and activity of motor units during periods of muscle maintenance, neuromuscular adaptation and aging.

\section{MICRORNAS IN RESPONSE TO MUSCULAR ACTIVITY}

It is clear that miRNAs are required for muscle development and regeneration; however their role in normal muscle maintenance and adaptation during adulthood has not been well characterized. In order to stimulate muscle adaptation in adulthood, there has to be increased demand, either mechanical or metabolic, placed on the muscle. Commonly, this is achieved through various modes of physical activity, such as resistance or aerobic exercise. For simplicity sake, this section will focus on literature that has shown changes in miRNA levels to either increased mechanical (i.e. resistance exercise) or metabolic (i.e. aerobic exercise) demand. Finally, we will examine emerging literature showing that miRNAs may be released from tissue during physical activity, potentially to act as signaling factors to peripheral tissues.

\subsection{MiRNAs in response to increased mechanical demand}

Our group was the first to demonstrate that miRNA levels could be modulated by changes in mechanical demand (128). We utilized a mouse model in which mechanical overload is placed on the plantaris muscle though the surgical removal of two synergist muscles, the gastrocnemius and soleus. Following 7 days of mechanical overload, the plantaris showed an $\sim 50 \%$ decrease in mature miR-1 and -133 levels, suggesting that perhaps this downregulation is required for muscle adaptation, including muscular hypertrophy (128). In agreement with the mouse data, in humans an acute bout of resistance exercise results in a significant decrease in miR-1 expression in skeletal muscle (129), perhaps in order to potentiate activation of the IGF1/AKT signaling cascade given that miR-1 has been shown to target $I g f-1$ and the $I g f-1 R$ (Igf-1 receptor) (130). In addition, there is evidence to suggest that the magnitude of change in miRNA expression following resistance exercise training is a predictor of how well a person will respond to the exercise (32). A recent study by Davidsen and colleagues examined whether changes in miRNA expression in the vastus lateralis muscle corresponded to differences in muscle hypertrophy. A cohort of young, adult males underwent 12 weeks of resistance training with post-hoc analysis separating the group into "low-responders" and "high-responders" based on each subject's change in lean body mass. Twenty-one miRNAs were profiled, all showing no significant change in the highresponder group, whereas the low-responder group showed a significant change in miR-451 (increase) and miR-378 (decrease), with a downward trend for miR-26a and miR-29a. Furthermore, the change in miR-378 expression showed a significant correlation $\left(\mathrm{R}^{2}=0.5 .1\right)$ to the change in lean body mass, leading the authors to speculate that perhaps decreases in miR-378 expression levels may hinder muscle accretion that accompanies resistance exercise (32). The link between miR-378 levels and muscle adaptation has not been well studied; however miR-378 has been shown to be positively regulated by MyoD, so perhaps miR-378 regulates a MyoD-dependent mechanism involved in skeletal muscle adaptation to exercise (131). 


\subsection{MiRNAs in response to increased metabolic demand}

Skeletal muscle is a large consumer of oxygen and is one of the primary tissues that determine basal metabolic rate. In response to increased metabolic demand, such as during aerobic exercise, skeletal muscle has the ability to adapt to this increase through mechanisms that include increasing capillarization, mitochondrial biogenesis, and increased metabolic enzyme content. Emerging evidence, while still correlative, suggest that metabolic changes in the muscle alter miRNA levels, which then may contribute to promoting adaptation. The first indication that miRNAs may be involved in regulating the metabolic phenotype came from work by van Rooji and coworkers (2009) who identified two miRNAs, miR-208b and miR-499, encoded within slow-twitch, type I myosin genes $M y h 7$ and $M y h 7 b$, respectively (37). The targeted deletion of miR-208b or miR-499 revealed that these two miRNAs were required to establish the slow-twitch fiber phenotype as null mice for either miRNA resulted in a muscle with significantly more fast-twitch fibers. Consistent with this finding, these knockout mice exhibited reduced exercise capacity when subjected to forced running (37).

Safdar and colleagues (2009) were the first to examine whether an acute bout of endurance exercise in mice was sufficient to modulate specific miRNAs known to target common genes associated with exercise adaptation (132). Using this candidate approach, they demonstrated that the exercise bout significantly increased the expression of miR-181, miR-1 and miR-107 by $37 \%, 40 \%$ and $56 \%$, respectively, and reduced miR-23 expression by $84 \%$. These changes in miRNA expression were associated with increased expression of the miR-23 target, $P g c-1 a$ (peroxisome proliferator-activated receptor gamma, coactivator 1 alpha), as well as downstream targets of PGC-1a involved in mitochondrial biogenesis (132). In addition, $P g c-1 a$ has been shown to be targeted by miR-696, another miRNA that is downregulated in response to endurance exercise (133). Further evidence suggesting that miRNA levels may control mitochondrial biogenesis was observed by Yamamoto et al. (2012), who demonstrated that a novel miRNA, miR-494 is suppressed following endurance exercise. This corresponded to a concomitant increase in gene targets involved mitochondrial biogenesis, including Pgc-1a, mtTFA (mitochondrial transcription factor A) and Foxj3 (forkhead box J3) (134). In addition to mitochondrial biogenesis, miRNAs may be involved in regulating adaptations involving oxygen deliver to the muscle via increased capillary density. Fernandes and coworkers (2012) examined miRNA levels in the soleus muscle of rats following swim training and found that miR-16 levels significantly decreased, paralleled by an increase in protein levels for VEGF (vascular endothelial growth factor) and its respective type 2 receptor (135). Vegfa has been validated as a target for miR-16 (136), and expression of $\mathrm{Vegf}$ is required for exercise-induced increased in capillary density in response to exercise (137). Therefore, these alterations within the VEGF pathway were thought to modulate angiogenesis, as the authors observed a concomitant increase in capillarization within the muscle (135).

In untrained human participants, 60 minutes of endurance exercise was reported to increase the expression of miR-1 and miR-133 in the vastus lateralis muscle, however, following 12 weeks of training the resting levels of miR-1, miR-133a, miR-133b and miR-206 were lower than pre-training (138). Interestingly, the changes observed following the acute 60 minute bout pre-training was abolished post-training (138), suggesting that miRNA levels in 
response to exercise are sensitive to training status. Similarly, Russell and colleagues (2013) reported increased miR-1, $-133 \mathrm{a},-133-\mathrm{b}$ and $-181 \mathrm{a}$ expression coupled with a decrease in miR-9, $-23 a,-23 b$ and -31 expression following an acute bout of exercise (139). These same authors found that following 10 days of training miR-1 and miR-31 expression was still increased and decreased, respectively, and that training had induced an increase in miR-29b expression. Further characterization of miR-31 revealed that there were negative correlations associated with miR-31 levels and HDAC4 and NRF1 (nuclear respiratory factor 1) levels, both predicated targets of miR-31 that the authors went on to validate (139). These findings support the results from animal studies, which showed the same pattern of expression for miR-1, -181 and -23 in response to endurance exercise (132). Employing a more comprehensive microarray approach, Keller et al. (2011), demonstrated that 6 weeks of cycling significantly decreased the expression of miR-1 and miR-133, along with miR-101 and miR-455 (140).

\subsection{Physical activity and circulating microRNA}

An emerging area of interest in the miRNA field is the presence of miRNAs in the circulation and their potentially to act as signaling molecules to affect peripheral tissues. With respect to physical activity, since skeletal muscle is the predominate tissue that is being activated, it would seem plausible that it may be the primary source contributing to altered miRNA levels in the circulation, however it cannot be ruled out that additional tissues are not involved. Radom-Aizik and colleagues (2010) were the first to look at the effects of acute exercise on changes in miRNA levels in the circulation, however they focused on miRNAs specifically within neutrophils (141). They followed up this work by examining other cell types in the circulation, including mononuclear cells (142) and natural killer cells (143). Baggish and colleagues (2011) investigated miRNAs in plasma from human subjects, choosing not to isolate a specific cell type, in response to either a bout of aerobic exercise or following a chronic training period (144). They observed that an acute bout of endurance exercise produced an increase in circulating levels of miR-146a, miR-222, miR-21 and miR-221. Furthermore, following the 90 day training period, the basal level of these miRNAs remained elevated in addition to miR-20a. Interestingly, even after the training period, circulating levels of these miRNAs still showed the transient increase following an acute bout of exercise (144). It should be noted that the authors utilized a candidate approach to focus their search on miRNA known to regulate genes involved in exercise adaptation and only included one muscle-specific (miR-133a) miRNA. With this in mind, Aoi et al. (2013) looked specifically at muscle-enriched miRNA (miR-1, miR-133a, miR-133b, miR-206, miR-208b, miR-486 and miR-499) and whether their expression level changed in response to either acute or chronic aerobic exercise (145). As would be expected, these miRNAs were found at extremely low levels in the plasma, however miR-486 was the most abundant and showed a significant change with aerobic exercise, decreasing with both acute and chronic exercise. The mechanism or the significance of this decrease is unclear, although miR-486 has been shown to target a negative regulator of insulin signaling (PTEN), leading the authors to postulate that it may be involved in glucose and metabolic regulation during exercise (145). 
Besides the type of exercise, the exercise modality may also influence the miRNAs found in the circulation, as resistance exercise has been shown to cause minor changes in miRNA levels at various time points following the exercise bout (146). Similarly, exercise bouts that primarily involve concentric muscle contractions show a differential response when compared to eccentric-based exercise (147). Eccentric-based exercise, which typically results in muscle damage, demonstrates a greater increase in the muscle-specific miRNAs which therefore may serve as useful biomarkers for muscle damage $(147,148)$. The idea that circulating miRNAs may serve as biomarkers has been around for some time in the cancer field, however only recently have groups been examining whether they have any relevance with respect to exercise capacity (149-151). Recently, a large cross-sectional study sought to determine if there was any relationship between circulating miRNAs levels and aerobic capacity, by stratifying individuals based on high or low maximal oxygen uptake $\left(\mathrm{VO}_{2} \max \right)$ (149). When examining results from both men and women, the authors found that individuals with low $\mathrm{VO}_{2}$ max had significantly higher levels of miR-210 and miR-222, 30\% and $20 \%$ respectively, when compared to participants with high $\mathrm{VO}_{2}$ max. In just men, miR-21 was also significantly elevated by $20 \%$ in individuals with low $\mathrm{VO}_{2} \max (149)$. Similarly, Mooren et al. (2014) sought to determine whether a specific subset of miRNAs (miR-1, -133, -206, -499, -208b, -21, and -155) correlated to aerobic capacity in trained marathon runners (151). Interestingly, only myomiRs miR-1, -133 and -206 demonstrated a significant positive correlation to an individual's $\mathrm{VO}_{2} \max (151)$. Recently, Nielsen and colleagues (2014) set out to define the temporal pattern of miRNA expression in the circulation following an acute bout and then in response to chronic training (152). These authors found that immediately post-exercise there was a rapid overall decrease in a subset of miRNAs, however in the hours following exercise (1-3) miRNA levels were generally increased, including miR-1, $-133 \mathrm{a}$ and $-133 \mathrm{~b}$, which is consistent with what others have shown at this time point (139). In addition, following chronic training, it appears that the majority of miRNAs were down-regulated, including miR-133, miR-29b and miR-92, similar to what has been reported in skeletal muscle in response to training $(138,140)$.

Collectively, the findings of these studies raise some intriguing questions regarding the roles of muscle-enriched miRNAs during exercise adaptation, specifically aerobic exercise. Acutely, an exercise bout increases the levels of muscle-specific miRNAs, while following training their levels return to baseline in the muscle, however this may be due to increased secretion into the circulation. This hypothetical model is summarized in Figure 2. Future investigations should examine miRNA levels both in skeletal muscle and in the circulation at multiple time points during exercise adaptation. Perhaps miRNA-mediated regulation may be one of the underlying mechanisms by which exercise produces beneficial effects on peripheral organs. This will no doubt be an exciting new area of research in the years to come.

\section{MICRORNA IN SKELETAL MUSCLE DISORDER AND ATROPHY}

Skeletal muscle disorder and atrophy can be divided into three major categories: primary muscular disorders, secondary muscular disorders and aging sarcopenia (153). Primary muscular disorders are the consequence of a disease that directly affects skeletal muscle, such as muscular dystrophies, inflammatory myopathies and congenital myopathies. 
Secondary muscular disorders are either disease-related, which include for example diabetes mellitus and chronic kidney disease, the result of neurodegenerative diseases, such as amyotrophic lateral sclerosis, or are a consequence of muscle disuse, resulting from bed-rest, immobilization or space flight. This section of the review will discuss the current understanding of miRNA regulation and its potential role in skeletal muscle dysfunction and atrophy. We will also discuss the miRNAs involved in rhabdomyosarcoma, a predominantly pediatric sarcoma derived from skeletal muscle progenitor cells.

\subsection{Primary muscular disorder}

Although primary muscular disorders are typically classified according to their clinical and pathological manifestations, these pathologies are almost always characterized by progressive skeletal muscle weakness and wasting, resulting in impaired locomotion (154). The major primary muscular disorders include several dystrophies such as Duchenne muscular dystrophy (DMD), myotonic dystrophy type 1 and 2, Becker muscular dystrophy (BMD), facioscapulohumeral muscular dystrophy (FSHD) and limb-girdle muscular dystrophy type 2A and 2B, as well as other myopathies, such as Miyoshi myopathy, nemaline myopathy, and the three inflammatory myopathies dermatomyositis, inclusion body myositis and polymyositis. Eisenberg and colleagues (2007) showed in a microarray study that 185 miRNAs are dysregulated in at least one of these ten primary muscular disorders, and the major portion of the dysregulated miRNAs was up-regulated (155). Among these miRNAs, miR-146b, miR-221, miR-155, miR-214, miR-222 and miR-34a were consistently up-regulated in at least nine of the ten different myopathies; moreover, most of the miRNAs have a similar pattern of expression in the diseases in which they were identified as differentially expressed in comparison to healthy human skeletal muscle. The study by Eisenberg and colleagues was the first to provide strong evidence that dysregulation of miRNA expression is a common feature of primary muscular disorders (See Table 2).

6.1.1. Duchenne muscular dystrophy-Numerous studies have used animal models to better understand the potential role of miRNAs in dystrophic diseases, as exemplified by the $m d x$ mouse. The $m d x$ mouse is a well-established model of DMD, the most common and severe form of dystrophy characterized by the absence of the cytoskeleton protein dystrophin $(55,156-160)$. We have previously shown that the muscle-specific miRNA (myomiR) miR-206 was up-regulated in the diaphragm of the $m d x$ mice, the most severely affected muscle in these dystrophic animals (159). The increase in miR-206 expression in skeletal muscle of $m d x$ mice was confirmed by others $(158,160)$, while the loss of miR-206 accelerates and exacerbates the dystrophic phenotype in this DMD model (46). In addition to miR-206, ten other miRNAs were found to be dysregulated in both the $m d x$ mouse and DMD patients (158). These authors proposed three classes of DMD-signature miRNAs, including regeneration miRNAs (up-regulated miRNAs: miR-31, miR-34c, miR-206, miR-335, miR-449, and miR-494), degenerative miRNAs (down-regulated miRNAs: miR-1, miR-29c, miR-135a) and inflammatory miRNAs (up-regulated miRNAs: miR-222 and miR-223). Interestingly, they reported that both administration of a histone deacetylase inhibitor and the overexpression of endothelial nitric oxide synthase rescued the dystrophic phenotype of the $m d x$ mouse apparently by normalizing miRNA expression (158). 
The findings from other studies have identified additional miRNAs that may offer alternative therapeutic strategies to improve the dystrophic phenotype. Cacchiarelli and coworkers found that expression of miR-31 was significantly increased in skeletal muscle and isolated myoblasts from DMD patients and was able to repress dystrophin expression $(158,161)$. This latter study showed that treating human myoblasts with exon-skipping oligonucleotide resulted in miR-31 inhibition, rescuing dystrophin expression. Moreover, administration of miR-29, a miRNA down-regulated in skeletal muscle of DMD patients $(55,158)$ improved dystrophy pathology by promoting regeneration and inhibiting fibrogenesis in $\mathrm{mdx}$ mice (55). An increased expression of miR-21 was also observed in DMD patients and in seven other primary muscular disorders $(155,157)$ and silencing this miRNA was shown to improve muscle dystrophy by reversing fibrosis in $m d x$ mice (157). The expression of the muscle-enriched miR-486 was reduced in patients with DMD, as well as in $m d x$ mice (116, 155). This miRNA was shown to alter cell cycle kinetics and the regeneration response following injury (116), suggesting that it may not be a relevant therapeutic strategy to ameliorate dystrophic disorders.

6.1.2. Myotonic dystrophy type 1 (DM1) and 2 (DM2)—DM1, the most frequent autosomal-dominant dystrophy in adults, is caused by the expansion of CTG repeats in the 3 ' untranslated region of the Dmpk (dystrophia myotonica-protein kinase) gene. Some studies have reported in muscle biopsies of DM1 patients an over-expression of miR-206, miR-210, and miR-335 whereas miR-29b, miR-29c, miR-33, miR-7 and miR-10a were downregulated (162-164). The dysregulation of miR-206, miR-29b and miR-29c is consistent with the changes observed in DMD patients $(55,158)$, suggesting that these miRNAs may have a role in muscle dysfunction related to these pathologies. An altered cellular distribution of the myomiR miR-206, miR-1 and miR-133b was observed in skeletal muscle of patients affected by DM1, while the changes in miR-1 expression remains controversial, as some studies reported either no change (163), a decrease (164) or an increase (162) in its expression. A recent study, using a fly model of DM1, showed that miR-10 over-expression increased lifespan (164), suggesting that this miRNA may be a relevant therapeutic target in DM1 patients.

DM2 displays milder clinical symptoms than DM1 and results from a tretanucleotidic repetition $(\mathrm{CCTG})_{\mathrm{n}}$ in the first intron of the CCHC-type zinc finger, nucleic acid binding protein $(C n b p)$ gene. Expression profiling of miRNA in muscle from DM2 patients revealed a dysregulation of 20 miRNAs, including the up-regulation of miR-133b and the downregulation of miR-133a, while most differentially expressed miRNAs did not share a similar pattern of expression with the skeletal muscle of DM1 subjects (165).

6.1.3. Facioscapulohumeral dystrophy (FSHD)—FSHD is an autosomal dominant disorder linked to the deletion of the D4Z4 repeats in the 4q35 subtelomeric region and most genes identified in this region are over-expressed in FSHD myoblasts, including the double homeobox genes Dux4 and Dux 4c (166). A recent study reported an increased expression of 21 miRNAs in myoblasts of FSDH patients, including the myomiRs miR-1, miR-133a, miR-133b and miR-206, as well as a decreased expression of eight miRNAs (167). These authors reported that the expression of 12 of the up-regulated miRNAs was also increased in 
cells transfected with DUX4C-expressing plasmid, suggesting that $D u x 4 c$ regulates the expression of these miRNAs in FSHD patients. Interestingly, miR-107, miR-152 and miR-15a were consistently up-regulated in both myoblasts (167) and skeletal muscle (155, 167) of FSHD patients; however, several dysregulated miRNAs showed the opposite pattern of expression in these two studies. A recent study reported that miR-411 was up-regulated in myoblasts of FSHD patients (168). These authors proposed that miR-411 could be involved in the myogenic defect observed in FSDH myoblasts (169), by blunting YAF2 (YY1 associated factor 2) expression, thereby leading to the up-regulation of YY1, a negative regulator of myogenesis. In addition, an up-regulation of YY1 was observed in immortalized human myoblasts over-expressing DUX4 (170). Although it remains to be elucidated, Dux4 gene may have a potential role in the up-regulation of YY1 and the myogenesis defects observed in FSHD, through the dysregulation of miR-411.

6.1.4. Inflammatory myopathies_-Inflammatory myopathies consist of a family of autoimmune/degenerative muscle diseases, including dermatomyositis, polymyositis and inclusion body myositis. Although these diseases differ in their clinical features, they share characteristics of chronic muscle inflammation and dysfunction (171). In their microarray study, Eisenberg and colleagues showed that the regulation of miRNA expression share some similarities in these three inflammatory diseases, as evidenced by the common upregulation of eight miRNAs (miR146b, miR-155, miR-21, miR-34a, miR-221, miR-214 and miR-222) (155). Recently, a decreased expression of the myomiRs miR-1, miR-133a and miR-133b was observed in skeletal muscle in the three subtypes of inflammatory myopathies, while miR-206 expression was only reduced in dermatomyositis patients (172). Tnf- $a$ (tumor necrosis factor $\alpha$ ) expression was inversely correlated with the reduced expression of these myomiRs in these inflammatory myopathies, consistent with the ability of TNF-a to repress the expression of these myogenic miRNAs and impair differentiation of $\mathrm{C} 2 \mathrm{C} 12$ myoblasts (172). Altogether, these results suggest that TNF-a contributes to the degenerative pathology of these inflammatory myopathies through the down-regulation of myomiRs. In addition, a decreased expression of miR-126 was observed in muscle of juvenile dermatomyositis patients with short duration of untreated disease, compared to patients with long duration of untreated disease and control subjects (173). Interestingly, this miRNA dysregulation was associated with the up-regulation of its predicted target Vcam-1 (vascular cell adhesion molecule 1), an adhesion factor involved in inflammation and tissue damage. This finding suggests a new potential mechanism involved in the juvenile dermatomyositis disease pathology.

\subsection{Secondary muscular disorder}

6.2.1. Amyotrophic lateral sclerosis (ALS)_ALS is a rapidly progressive neurodegenerative disorder affecting motor neurons, and leading to muscle denervation, atrophy, paralysis and ultimately death. Several studies have investigated the regulation of miRNAs in the central nervous system of ALS patients $(19,174)$ but information is limited in skeletal muscle. A recent study showed that miR-206 was dramatically up-regulated in skeletal muscle in a mouse model of ALS, while deficiency of miR-206 in this animal model accelerated the progression of the disease (47). These authors demonstrated that miR-206 promotes regeneration of neuromuscular synapses after nerve injury, most probably through 
the inactivation of $\mathrm{Hdac} 4$, suggesting that miR-206 could slow ALS progression. The increased expression of miR-206 was confirmed in ALS patients, but the changes remained moderate compared to those observed in the ALS mouse model $(175,176)$. Recently, Bruneteau and colleagues (2013) investigated whether the miR-206/Hdac4 pathway plays a role in the compensatory muscle reinnervation in ALS patients (176). They showed that Hdac4 up-regulation was higher in patients with rapidly progressive ALS compared to longterm ALS survivors, while the moderate increase in miR-206 expression were similar between these two groups. Although it remains to be tested, a therapeutic approach causing an increase in miR-206 expression in skeletal muscle may be beneficial to repress Hdac4 expression and reduce disease progression in ALS patients. In addition to miR-206, miR-23a, miR-29b and miR-455 were also up-regulated in skeletal muscle of ALS patients (175). Interestingly, these authors showed that miR-23a represses the expression of $P g c-1 a$, a master regulator of mitochondrial function that is impaired in ALS patients. These finding suggests that miR-23a could be involved in the skeletal muscle mitochondria dysfunction in ALS patients.

\subsubsection{Disease-related muscular disorder}

6.2.2.1. Diabetes mellitus: Diabetes mellitus is a metabolic disease characterized by the presence of a hyperglycemic state resulting from impairments in insulin release and/or function. Skeletal muscle is the primary site of post-prandial glucose intake, and muscle atrophy and metabolic perturbations commonly observed in both type 1 (T1DM) and 2 (T2DM) diabetic patients (177). Over the last five years, cumulative evidence has showed that miRNAs are involved in skeletal muscle dysfunction associated with diabetes mellitus (178). A decreased expression of miR-23a, a miRNA reported to repress the expression of the atrogenes Murf1 (muscle ring finger 1) and Fbxo32 (F-box protein 32), was observed in rodent models of diabetes mellitus $(179,180)$, suggesting that miR-23a dysregulation could be associated with the catabolic state of diabetic skeletal muscle. Expression of miRNAs let-7a and let-7d was increased in primary muscle cells of T2DM patients, and this finding was consistent with the down-regulation of II-13 (interleukin-13), a validated target gene (181). These authors proposed that let-7a and let-7d could have a role in the perturbation of glucose homeostasis in diabetes through the dysregulation of II-13.

Other miRNAs were proposed to be involved in the regulation of glucose homeostasis and insulin resistance in diabetes. Expression of miR-144 (182) and miR-135a (183) were increased in two rodent models of T2DM, and these miRNA were shown to repress the expression of Irs-1 and Irs-2, respectively, two components of the insulin/AKT signaling pathway. Recently, Zhang and colleagues (2013) showed in C2C12 myotubes that miR-106b represses the expression of $M f n 2$ (mitofusin 2), a gene encoding a dynamin-related protein involved in the regulation of mitochondrial morphology and function (184). Moreover, an increased expression of miR-106b in skeletal muscle was observed in T2DM patients and insulin resistant mice $(185,186)$, while $M$ fn2 expression was down-regulated in skeletal muscle of T2DM patients (187). Altogether, these findings provide evidence that inhibiting miR-106b may be a beneficial strategy to reduce insulin resistance in type 2 diabetes. A reduced expression of miR-24 in skeletal muscle of diabetic rats was associated with an increased expression of its direct target p38 MAPK (p38 mitogen-activated protein kinase) 
(180), but the specific relationship among miR-24, p38 MAPK and insulin resistance remains to be fully examined. Finally, miR-133a and miR-206 were down-regulated in skeletal muscle of T2DM patients, while no changes were observed for miR-1 and miR-133b (185). High fasting glycaemia was associated with low miR-133a, suggesting that miR-133a may be a relevant molecular marker for insulin resistance.

6.2.2.2. Chronic kidney disease (CKD): miRNAs were recently suggested to have a role in skeletal muscle wasting associated with CKD (188). Profiling of miRNA expression in skeletal muscle of mice with CKD revealed a dysregulation of 12 miRNAs (89). Among these miRNAs, miR-29a and miR-29b were down-regulated, and may contribute to the impaired muscle differentiation associated with CKD through the activation of YY1. A decrease in the expression of miR-486 was observed in this CDK model, with miR-486 over-expression blunting the muscle atrophy associated with this model by blocking the activation of the FOXO1 (forkhead transcription factor O1)/atrogene pathway (189). Currently, the regulation of miRNA expression remains to be investigated in skeletal muscle of patients with CKD.

6.2.2.3. Chronic obstructive pulmonary disease (COPD): COPD is another disease associated with skeletal muscle wasting and dysfunction. Analysis of miRNA expression in the skeletal muscle of COPD patients revealed a decreased expression of miR-1, whereas no change in miR-133 and miR-206 expression was observed (190). The decreased expression of miR-1 was associated with an increased level of Igf-ImRNA and HDAC4 protein, two validated miR-1 targets. Assessment of circulating myomiRs revealed an increased level of miR-1, miR-133, miR-206, and miR-499 in the plasma of the COPD patients (191).

6.2.2.4. Glucocorticoid induced-atrophy: Glucocorticoid is an endocrine hormone released in several pathological states (sepsis, renal failure, fasting, immobilization, metabolic acidosis, etc.) associated with skeletal muscle atrophy and weakness (192). A recent study showed that the glucocorticoid dexamethasone (Dex) induces skeletal muscle atrophy and stimulates miR-1 expression through glucocorticoid receptor and myostatin (193). These authors proposed a model by which miR-1 inhibits the expression of HSP70 (heat shock protein 70) protein, thereby reducing AKT phosphorylation and enhancing the activation of FOXO3 and atrophy-related proteins. Although FOXO3 was recently shown to be directly down-regulated by miR-155 in glioma cells (194), to our knowledge, no miRNAs have been identified to directly target FOXO3 in skeletal muscle. These results provide evidence that miR-1 is a catabolic miRNA involved in glucocorticoid-induced skeletal muscle atrophy. In addition to the increase in miR-1 levels, Dex reduced miR-27 content in myotubes, a result consistent with the increased expression of its validated target myostatin $(195,196)$. These findings suggest that myostatin could be a central regulator of the catabolic response through its interaction with miR-1 and miR-27. Furthermore, Dex treatment reduced the level of miR-23 in C2C12 myotubes through a mechanism involving attenuated calcineurin signaling pathway and miR-23 packaging into exoxomes (197). Although miR-23a expression was not affected by Dex treatment in skeletal muscle, this miRNA prevented Dex-induced atrophy, most probably by repressing the translation of the ubiquitin-ligases MURF1 and FBXO32 
(also called MAFBX or ATROGIN1) (198). These findings provide additional evidence that miR-23 may be a beneficial target to prevent muscle atrophy associated with catabolic states.

6.2.3. Disuse-related muscular disorder-To our knowledge, only a few studies have examined the expression of miRNA in skeletal muscle atrophy in response to disuse in animals $(133,199,200)$ or humans $(201,202)$. Allen and colleagues $(2009)$ reported a decreased level of miR-206 expression in the gastrocnemius muscle of mice after a spaceflight, while a trend toward a decrease in miR-133a expression was also note (199). Given that miR-206 is more abundant in slow oxidative than fast glycolytic muscles (128), it was suggested that miR-206 down-regulation in spaceflight muscle may reflect the slow-tofast shift associated with microgravity exposure. We previously observed that the expression of miR-499 and miR-208b, two myomiRs encoded by $M y h 7 b$ and $M y h 7$ genes, respectively, were down-regulated after 28 days of hind limb unloading (200). This miRNA dysregulation was associated with the up-regulation of Sox6 (SRY-box containing gene 6), a validated target gene of miR-499 and miR-208b known to repress $\beta$-MHC expression in skeletal muscle (37). These findings provide evidence that the dysregulation of these two components of the myomiR network (203), may be involved in the slow-to-fast transition associated with unloading. In addition to the effect on fiber type, miR-499 and miR-208a were shown to repress myostatin expression $(45,204)$, a repressor of muscle growth that is over-expressed in skeletal muscle following hind limb suspension (205). Among the four upregulated miRNAs observed after five days of hind limb immobilization in mice, the increase in miR-696 level was associated with a decrease in the expression of its predicted target gene Pgc-1a (133). These authors demonstrated that miR-696 represses Pgc-1a translation in vitro, suggesting that miR-696 is involved in the impaired oxidative metabolism observed in this model of physical inactivity. The miRNA expression profile performed in human skeletal muscle after 10 days of bed rest revealed the dysregulation of 15 miRNAs, including the down-regulation of miR-206 and miR-23a (201). Although the decreased level of miR-23a was not confirmed by others after seven days of bed rest in human ${ }^{199}$, this result provides additional evidence that this miRNA may be involved in the atrophic response associated with this catabolic state $(179,180)$.

\subsection{Aging}

Sarcopenia is characterized by a progressive decline in skeletal muscle mass and function that occurs with aging. Recent lines of evidence indicate that miRNA expression is modulated in skeletal muscle during aging. Profiling of miRNA expression in skeletal muscle of mice (206) and rhesus monkeys (207) revealed that several miRNAs involved in the regulation of myogenesis are dysregulated during aging. Compared to young animals, skeletal muscle from both old mice and monkeys showed a decreased expression of miR-181a, a change that could promote the expression of its predicted target Acvr2a (activin receptor IIA), a gene shown to inhibit myogenic cell proliferation through Smad2/3 phosphorylation (208). Therefore, miR-181a down-regulation may impair the proliferation of satellite cells and their ability to repair damaged fibers in aged muscle. A reduction in miR-221 level, a miRNA involved in the regulation of myogenic differentiation (209), was reported in skeletal muscle of aged mice (206), whereas a decline in miR-489, a miRNA highly expressed in quiescent satellite cells (67), was observed in muscle of aged monkeys 
(207). Drummond and colleagues (2011) observed in skeletal muscle of aged human subjects an increased content of let- $7 \mathrm{~b}$ and let-7e, a finding associated with the downregulation of several let-7 target genes involved in the regulation of cell cycle (210). Currently, it remains to be examined whether these myogenesis-related miRNAs contribute to the loss of muscle mass in the elderly. Increased levels of the primary miRNAs primiR-1-1, pri-miR-1-2, pri-miR-133a-1 and pri-miR-133a-2 were found in old compared to young human subjects, while no changes were observed for the mature miRNAs (129). These authors showed that miR-1 level was reduced in the young, but not old subjects after an acute bout of resistance exercise combined with essential amino acid ingestion (129). Conversely, old human subjects exhibited a reduction in miR-1 expression in response to 12 weeks of resistance training, while this change was not assessed in young individuals (211). The expression of miR-451 was increased in skeletal muscle of old compared to young monkeys (207), and a similar results was reported in "low responders" compared to "high responders" to resistance exercise (32). Additional experiments are required to elucidate whether miR-1, which was shown to inhibit various component of the IGF-I/AKT signaling pathway (130), and miR-451, could be involved in the muscle resistance to anabolic stimuli in the elderly.

\subsection{Rhabdomyosarcoma (RMS)}

RMS, the most common pediatric soft tissue sarcoma, is derived from skeletal muscle progenitor cells that maintain a proliferative capacity but poorly differentiate (212). As miRNAs play a role in the regulation of both tumorigenesis and myogenesis, intensive efforts have been made to identify miRNAs involved in RMS tumor (213). A dramatic decrease in miR-1 and miR-206 expression was reported in RMS cell line and human RMS specimens, resulting in the up-regulation of the oncogene $c$-Met, a validated target gene (214). In addition to the down-regulation of miR-1 and miR-206, decreased levels of miR-133a and miR-133b were also observed in $\operatorname{RMS}$ tumor samples $(88,215,216)$, while low miR-206 expression was shown to correlate with poor overall survival in RMS patients (216). The fact that the growth and migration of cells derived from a RMS lineage was reduced after transfection of miR-1 and miR-206 suggests that these miRNAs could be potent tumor suppressors in RMS (214).

Several non-myomiRs have also been reported to regulate tumor formation in RMS cell lines. MiR-29, which promotes myogenic differentiation, is repressed by the NFKB/YY1 pathway in RMS cells and primary tumors (88). The inhibition of tumor growth and stimulation of differentiation in RMS cells ectopically over-expressing miR-29 suggests that this miRNA acts as a RMS tumor suppressor. MiR-203 is also down-regulated in both RMS biopsies and cell lines, and its re-expression in RMS cells impaired the cell migration and proliferation, and promoted myogenic differentiation (217). These authors provided evidence that the tumor suppressive effect of miR-203 results from the inhibition of the Notch pathway and the activation of the JAK1 (Janus kinase 1)/STAT1 (signal transducer and activator of transcription 1)/STAT3 pathway. A reduced level of miR-26a was also reported in both RMS cell lines and tumor samples, a result associated with a concomitant up-regulation of Ezh2, a negative regulator of muscle differentiation (218). Recently, Sarver and co-workers (2010) identified miR-183 as a potential oncogenic miRNA, through its 
ability to blunt the expression of the two tumor suppressors Egr1 (early growth response 1) and Pten (219).

\section{CONCLUSIONS}

Over the past decade and a half, miRNAs have emerged as another key component of gene regulation underlying the skeletal muscle phenotype. In vitro and in vivo studies have confirmed their important role in myogenesis, however whether they function to maintain muscle throughout adulthood is less clear. Furthermore, during periods of muscle adaptation there are alterations in gene expression, with mounting evidence showing that miRNA accompany these changes, however evidence linking cause-and-effect between gene expression and miRNA levels is still lacking. With this in mind, future research should focus on the extent that miRNAs are involved in maintenance of adult skeletal muscle with the hope of identifying whether the dysregulation of miRNA expression is casual to the progressive loss of muscle mass with disuse or aging. Furthermore, miRNA have been shown to be dysregulated in various myopathies, so both cases represent possibilities where miRNAs may be therapeutic targets that can be modulated. Similarly, miRNAs could act as therapeutics themselves by harnessing their ability to post-transcriptionally regulate gene targets that are dysfunctional resulting in a disease phenotype. Finally, defining the extent to which miRNAs are involved in muscle adaptation to exercise may provide an avenue to develop more effective training programs for those populations in which skeletal muscle adaptation is compromised, such as during aging. Regardless of these challenges, the field of miRNAs in skeletal muscle biology is still in its infancy with many exciting questions still left to be answered.

\section{Acknowledgments}

This work was supported by the National Institute of Health (AR061939) to JJM. TJK and TC contributed equally to this article.

\section{REFERENCES}

1. Lee RC, Feinbaum RL, Ambros V. The C. elegans heterochronic gene lin-4 encodes small RNAs with antisense complementarity to lin-14. Cell. 1993; 75(5):843-854. [PubMed: 8252621]

2. Wightman B, Ha I, Ruvkun G. Posttranscriptional regulation of the heterochronic gene lin-14 by lin-4 mediates temporal pattern formation in C. elegans. Cell. 1993; 75(5):855-862. [PubMed: 8252622]

3. Lee R, Feinbaum R, Ambros V. A short history of a short RNA. Cell. 2004; 116(2 Suppl):S89-S92. $1 \mathrm{p}$ following S96. [PubMed: 15055592]

4. Ruvkun G, Wightman B, Ha I. The 20 years it took to recognize the importance of tiny RNAs. Cell. 2004; 116(2 Suppl):S93-S96. 2 p following S96. [PubMed: 15055593]

5. Pasquinelli AE, Reinhart BJ, Slack F, Martindale MQ, Kuroda MI, Maller B, Hayward DC, Ball EE, Degnan B, Muller P, Spring J, Srinivasan A, Fishman M, Finnerty J, Corbo J, Levine M, Leahy P, Davidson E, Ruvkun G. Conservation of the sequence and temporal expression of let-7 heterochronic regulatory RNA. Nature. 2000; 408(6808):86-89. [PubMed: 11081512]

6. Lagos-Quintana M, Rauhut R, Lendeckel W, Tuschl T. Identification of novel genes coding for small expressed RNAs. Science. 2001; 294(5543):853-858. [PubMed: 11679670]

7. Lau NC, Lim LP, Weinstein EG, Bartel DP. An abundant class of tiny RNAs with probable regulatory roles in Caenorhabditis elegans. Science. 2001; 294(5543):858-862. [PubMed: 11679671] 
8. Lee RC, Ambros V. An extensive class of small RNAs in Caenorhabditis elegans. Science. 2001; 294(5543):862-864. [PubMed: 11679672]

9. Lagos-Quintana M, Rauhut R, Yalcin A, Meyer J, Lendeckel W, Tuschl T. Identification of tissuespecific microRNAs from mouse. Curr Biol. 2002; 12(9):735-739. [PubMed: 12007417]

10. Cai X, Hagedorn CH, Cullen BR. Human microRNAs are processed from capped, polyadenylated transcripts that can also function as mRNAs. RNA. 2004; 10(12):1957-1966. [PubMed: 15525708]

11. Lee Y, Kim M, Han J, Yeom KH, Lee S, Baek SH, Kim VN. MicroRNA genes are transcribed by RNA polymerase II. EMBO J. 2004; 23(20):4051-4060. [PubMed: 15372072]

12. Godnic I, Zorc M, Jevsinek Skok D, Calin GA, Horvat S, Dove P, Kovac M, Kunej T. Genomewide and species-wide in silico screening for intragenic MicroRNAs in human, mouse and chicken. PLoS One. 2013; 8(6):e65165. [PubMed: 23762306]

13. Rodriguez A, Griffiths-Jones S, Ashurst JL, Bradley A. Identification of mammalian microRNA host genes and transcription units. Genome Res. 2004; 14(10A):1902-1910. [PubMed: 15364901]

14. Monteys AM, Spengler RM, Wan J, Tecedor L, Lennox KA, Xing Y, Davidson BL. Structure and activity of putative intronic miRNA promoters. RNA. 2010; 16(3):495-505. [PubMed: 20075166]

15. Gregory RI, Yan KP, Amuthan G, Chendrimada T, Doratotaj B, Cooch N, Shiekhattar R. The Microprocessor complex mediates the genesis of microRNAs. Nature. 2004; 432(7014):235-240. [PubMed: 15531877]

16. Landthaler M, Yalcin A, Tuschl T. The human DiGeorge syndrome critical region gene 8 and Its D. melanogaster homolog are required for miRNA biogenesis. Curr Biol. 2004; 14(23):2162-2167. [PubMed: 15589161]

17. Han J, Lee Y, Yeom KH, Nam JW, Heo I, Rhee JK, Sohn SY, Cho Y, Zhang BT, Kim VN. Molecular basis for the recognition of primary microRNAs by the Drosha-DGCR8 complex. Cell. 2006; 125(5):887-901. [PubMed: 16751099]

18. Freischmidt A, Muller K, Ludolph AC, Weishaupt JH. Systemic dysregulation of TDP-43 binding microRNAs in amyotrophic lateral sclerosis. Acta Neuropathol Commun. 2013; 1(1):42. [PubMed: 24252274]

19. Davis BN, Hilyard AC, Lagna G, Hata A. SMAD proteins control DROSHA-mediated microRNA maturation. Nature. 2008; 454(7200):56-61. [PubMed: 18548003]

20. Yamanaka Y, Tagawa H, Takahashi N, Watanabe A, Guo YM, Iwamoto K, Yamashita J, Saitoh H, Kameoka Y, Shimizu N, Ichinohasama R, Sawada K. Aberrant overexpression of microRNAs activate AKT signaling via down-regulation of tumor suppressors in natural killer-cell lymphoma/ leukemia. Blood. 2009; 114(15):3265-3275. [PubMed: 19641183]

21. Bohnsack MT, Czaplinski K, Gorlich D. Exportin 5 is a RanGTP-dependent dsRNA-binding protein that mediates nuclear export of pre-miRNAs. RNA. 2004; 10(2):185-191. [PubMed: 14730017]

22. Yi R, Qin Y, Macara IG, Cullen BR. Exportin-5 mediates the nuclear export of pre-microRNAs and short hairpin RNAs. Genes Dev. 2003; 17(24):3011-3016. [PubMed: 14681208]

23. Macrae IJ, Zhou K, Li F, Repic A, Brooks AN, Cande WZ, Adams PD, Doudna JA. Structural basis for double-stranded RNA processing by Dicer. Science. 2006; 311(5758):195-198. [PubMed: 16410517]

24. Pasquinelli AE. MicroRNAs and their targets: recognition, regulation and an emerging reciprocal relationship. Nat Rev Genet. 2012; 13(4):271-282. [PubMed: 22411466]

25. Finnegan EF, Pasquinelli AE. MicroRNA biogenesis: regulating the regulators. Crit Rev Biochem Mol Biol. 2013; 48(1):51-68. [PubMed: 23163351]

26. Pilotte J, Dupont-Versteegden EE, Vanderklish PW. Widespread regulation of miRNA biogenesis at the Dicer step by the cold-inducible RNA-binding protein, RBM3. PLoS One. 2011; 6(12):e28446. [PubMed: 22145045]

27. Dupont-Versteegden EE, Nagarajan R, Beggs ML, Bearden ED, Simpson PM, Peterson CA. Identification of cold-shock protein RBM3 as a possible regulator of skeletal muscle size through expression profiling. Am J Physiol Regul Integr Comp Physiol. 2008; 295(4):R1263-R1273. [PubMed: 18753264] 
28. Yang JS, Lai EC. Alternative miRNA biogenesis pathways and the interpretation of core miRNA pathway mutants. Mol Cell. 2011; 43(6):892-903. [PubMed: 21925378]

29. Langenberger D, Cakir MV, Hoffmann S, Stadler PF. Dicer-processed small RNAs: rules and exceptions. J Exp Zool B Mol Dev Evol. 2012; 320(1):35-46. [PubMed: 23165937]

30. Cheloufi S, Dos Santos CO, Chong MM, Hannon GJ. A dicer-independent miRNA biogenesis pathway that requires Ago catalysis. Nature. 2010; 465(7298):584-589. [PubMed: 20424607]

31. Dmitriev P, Barat A, Polesskaya A, O’Connell MJ, Robert T, Dessen P, Walsh TA, Lazar V, Turki A, Carnac G, Laoudj-Chenivesse D, Lipinski M, Vassetzky YS. Simultaneous miRNA and mRNA transcriptome profiling of human myoblasts reveals a novel set of myogenic differentiationassociated miRNAs and their target genes. BMC Genomics. 2013; 14:265. [PubMed: 23597168]

32. Davidsen PK, Gallagher IJ, Hartman JW, Tarnopolsky MA, Dela F, Helge JW, Timmons JA, Phillips SM. High responders to resistance exercise training demonstrate differential regulation of skeletal muscle microRNA expression. J Appl Physiol (1985). 2011; 110(2):309-317. [PubMed: 21030674]

33. Patrick DM, Zhang CC, Tao Y, Yao H, Qi X, Schwartz RJ, Huang LJ-S, Olson EN, N E. Defective erythroid differentiation in miR-451 mutant mice mediated by 14-3-3zeta. Genes Dev. 2010; 24:1614-1619. [PubMed: 20679397]

34. Sempere LF, Freemantle S, Pitha-Rowe I, Moss E, Dmitrovsky E, Ambros V. Expression profiling of mammalian microRNAs uncovers a subset of brain-expressed microRNAs with possible roles in murine and human neuronal differentiation. Genome Biol. 2004; 5(3):R13. [PubMed: 15003116]

35. McCarthy JJ. MicroRNA-206: the skeletal muscle-specific myomiR. Biochim Biophys Acta. 2008; 1779(11):682-691. [PubMed: 18381085]

36. Small EM, O'Rourke JR, Moresi V, Sutherland LB, McAnally J, Gerard RD, Richardson JA, Olson EN. Regulation of PI3-kinase/Akt signaling by muscle-enriched microRNA-486. Proc Natl Acad Sci U S A. 2010; 107(9):4218-4223. [PubMed: 20142475]

37. van Rooij E, Quiat D, Johnson BA, Sutherland LB, Qi X, Richardson JA, Kelm RJ Jr, Olson EN. A family of microRNAs encoded by myosin genes governs myosin expression and muscle performance. Dev Cell. 2009; 17(5):662-673. [PubMed: 19922871]

38. van Rooij E, Sutherland LB, Qi X, Richardson JA, Hill J, Olson EN. Control of stress-dependent cardiac growth and gene expression by a microRNA. Science. 2007; 316(5824):575-579. [PubMed: 17379774]

39. McCarthy JJ, Esser KA. MicroRNA-1 and microRNA-133a expression are decreased during skeletal muscle hypertrophy. J Appl Physiol. 2007; 102(1):306-313. [PubMed: 17008435]

40. Liu N, Olson EN. MicroRNA regulatory networks in cardiovascular development. Dev Cell. 2010; 18(4):510-525. [PubMed: 20412767]

41. Lim LP, Lau NC, Garrett-Engele P, Grimson A, Schelter JM, Castle J, Bartel DP, Linsley PS, Johnson JM. Microarray analysis shows that some microRNAs downregulate large numbers of target mRNAs. Nature. 2005; 433(7027):769-773. [PubMed: 15685193]

42. Sokol NS, Ambros V. Mesodermally expressed Drosophila microRNA-1 is regulated by Twist and is required in muscles during larval growth. Genes Dev. 2005; 19(19):2343-2354. [PubMed: 16166373]

43. Liu Y, Li M, Ma J, Zhang J, Zhou C, Wang T, Gao X, Li X. Identification of differences in microRNA transcriptomes between porcine oxidative and glycolytic skeletal muscles. BMC Mol Biol. 2013; 14:7. [PubMed: 23419046]

44. Muroya S, Taniguchi M, Shibata M, Oe M, Ojima K, Nakajima I, Chikuni K. Profiling of differentially expressed microRNA and the bioinformatic target gene analyses in bovine fast- and slow-type muscles by massively parallel sequencing. J Anim Sci. 2013; 91(1):90-103. [PubMed: 23100578]

45. Callis TE, Pandya K, Seok HY, Tang RH, Tatsuguchi M, Huang ZP, Chen JF, Deng Z, Gunn B, Shumate J, Willis MS, Selzman CH, Wang DZ. MicroRNA-208a is a regulator of cardiac hypertrophy and conduction in mice. J Clin Invest. 2009; 119(9):2772-2786. [PubMed: 19726871]

46. Liu N, Williams AH, Maxeiner JM, Bezprozvannaya S, Shelton JM, Richardson JA, Bassel-Duby R, Olson EN. microRNA-206 promotes skeletal muscle regeneration and delays progression of 
Duchenne muscular dystrophy in mice. J Clin Invest. 2012; 122(6):2054-2065. [PubMed: 22546853]

47. Williams AH, Valdez G, Moresi V, Qi X, McAnally J, Elliott JL, Bassel-Duby R, Sanes JR, Olson EN. MicroRNA-206 delays ALS progression and promotes regeneration of neuromuscular synapses in mice. Science. 2009; 326(5959):1549-1554. [PubMed: 20007902]

48. Zhao Y, Ransom JF, Li A, Vedantham V, von Drehle M, Muth AN, Tsuchihashi T, McManus MT, Schwartz RJ, Srivastava D. Dysregulation of cardiogenesis, cardiac conduction, and cell cycle in mice lacking miRNA-1-2. Cell. 2007; 129(2):303-317. [PubMed: 17397913]

49. Heyer MP, Pani AK, Smeyne RJ, Kenny PJ, Feng G. Normal midbrain dopaminergic neuron development and function in miR-133b mutant mice. J Neurosci. 2012; 32(32):10887-10894. [PubMed: 22875923]

50. Leung AK, Sharp PA. MicroRNA functions in stress responses. Mol Cell. 2010; 40(2):205-215. [PubMed: 20965416]

51. Kim HK, Lee YS, Sivaprasad U, Malhotra A, Dutta A. Muscle-specific microRNA miR-206 promotes muscle differentiation. J Cell Biol. 2006; 174(5):677-687. [PubMed: 16923828]

52. Chen JF, Mandel EM, Thomson JM, Wu Q, Callis TE, Hammond SM, Conlon FL, Wang DZ. The role of microRNA-1 and microRNA-133 in skeletal muscle proliferation and differentiation. Nat Genet. 2006; 38(2):228-233. [PubMed: 16380711]

53. Liu N, Bezprozvannaya S, Williams AH, Qi X, Richardson JA, Bassel-Duby R, Olson EN. microRNA-133a regulates cardiomyocyte proliferation and suppresses smooth muscle gene expression in the heart. Genes Dev. 2008; 22(23):3242-3254. [PubMed: 19015276]

54. Liu N, Bezprozvannaya S, Shelton JM, Frisard MI, Hulver MW, McMillan RP, Wu Y, Voelker KA, Grange RW, Richardson JA, Bassel-Duby R, Olson EN. Mice lacking microRNA 133a develop dynamin 2-dependent centronuclear myopathy. J Clin Invest. 2011; 121(8):3258-3268. [PubMed: 21737882]

55. Bentzinger CF, Wang YX, Rudnicki MA. Building muscle: molecular regulation of myogenesis. Cold Spring Harb Perspect Biol. 2012; 4(2)

56. Buckingham M. Skeletal muscle formation in vertebrates. Curr Opin Genet Dev. 2001; 11(4):440448. [PubMed: 11448631]

57. Buckingham M. Myogenic progenitor cells and skeletal myogenesis in vertebrates. Curr Opin Genet Dev. 2006; 16(5):525-532. [PubMed: 16930987]

58. Buckingham M, Rigby PW. Gene Regulatory Networks and Transcriptional Mechanisms that Control Myogenesis. Dev Cell. 2014; 28(3):225-238. [PubMed: 24525185]

59. Brack AS, Rando TA. Tissue-specific stem cells: lessons from the skeletal muscle satellite cell. Cell Stem Cell. 2012; 10(5):504-514. [PubMed: 22560074]

60. Yablonka-Reuveni Z. The skeletal muscle satellite cell: still young and fascinating at 50 . J Histochem Cytochem. 2011; 59(12):1041-1059. [PubMed: 22147605]

61. Yin H, Price F, Rudnicki MA. Satellite cells and the muscle stem cell niche. Physiol Rev. 2013; 93(1):23-67. [PubMed: 23303905]

62. Buckingham M, Bajard L, Chang T, Daubas P, Hadchouel J, Meilhac S, Montarras D, Rocancourt D, Relaix F. The formation of skeletal muscle: from somite to limb. J Anat. 2003; 202(1):59-68. [PubMed: 12587921]

63. Chen Z, Liang S, Zhao Y, Han Z. miR-92b regulates Mef2 levels through a negative-feedback circuit during Drosophila muscle development. Development. 2012; 139(19):3543-3552. [PubMed: 22899845]

64. Gagan J, Dey BK, Layer R, Yan Z, Dutta A. Notch3 and Mef2c proteins are mutually antagonistic via Mkp1 protein and miR-1/206 microRNAs in differentiating myoblasts. J Biol Chem. 2012; 287(48):40360-40370. [PubMed: 23055528]

65. Ikeda S, He A, Kong SW, Lu J, Bejar R, Bodyak N, Lee KH, Ma Q, Kang PM, Golub TR, Pu WT. MicroRNA-1 negatively regulates expression of the hypertrophy-associated calmodulin and Mef2a genes. Mol Cell Biol. 2009; 29(8):2193-2204. [PubMed: 19188439]

66. Seok HY, Tatsuguchi M, Callis TE, He A, Pu WT, Wang DZ. miR-155 inhibits expression of the MEF2A protein to repress skeletal muscle differentiation. J Biol Chem. 2011; 286(41):3533935346. [PubMed: 21868385] 
67. Cheung TH, Quach NL, Charville GW, Liu L, Park L, Edalati A, Yoo B, Hoang P, Rando TA. Maintenance of muscle stem-cell quiescence by microRNA-489. Nature. 2012; 482(7386):524528. [PubMed: 22358842]

68. Crist CG, Montarras D, Buckingham M. Muscle satellite cells are primed for myogenesis but maintain quiescence with sequestration of Myf5 mRNA targeted by microRNA-31 in mRNP granules. Cell Stem Cell. 2012; 11(1):118-126. [PubMed: 22770245]

69. Huang Z, Chen X, Yu B, He J, Chen D. MicroRNA-27a promotes myoblast proliferation by targeting myostatin. Biochem Biophys Res Commun. 2012; 423(2):265-269. [PubMed: 22640741]

70. McFarlane C, Vajjala A, Arigela H, Lokireddy S, Ge X, Bonala S, Manickam R, Kambadur R, Sharma M. Negative Auto-Regulation of Myostatin Expression is Mediated by Smad3 and MicroRNA-27. PLoS One. 2014; 9(1):e87687. [PubMed: 24498167]

71. Chen Y, Gelfond J, McManus LM, Shireman PK. Temporal microRNA expression during in vitro myogenic progenitor cell proliferation and differentiation: regulation of proliferation by miR- 682 . Physiol Genomics. 2011; 43(10):621-630. [PubMed: 20841498]

72. Chen JF, Tao Y, Li J, Deng Z, Yan Z, Xiao X, Wang DZ. microRNA-1 and microRNA-206 regulate skeletal muscle satellite cell proliferation and differentiation by repressing Pax7. J Cell Biol. 2010; 190(5):867-879. [PubMed: 20819939]

73. Dey BK, Gagan J, Dutta A. miR-206 and -486 induce myoblast differentiation by downregulating Pax7. Mol Cell Biol. 2011; 31(1):203-214. [PubMed: 21041476]

74. Winbanks CE, Wang B, Beyer C, Koh P, White L, Kantharidis P, Gregorevic P. TGF-beta regulates miR-206 and miR-29 to control myogenic differentiation through regulation of HDAC4. J Biol Chem. 2011; 286(16):13805-13814. [PubMed: 21324893]

75. Zhang D, Li X, Chen C, Li Y, Zhao L, Jing Y, Liu W, Wang X, Zhang Y, Xia H, Chang Y, Gao X, Yan J, Ying H. Attenuation of p38-mediated miR-1/133 expression facilitates myoblast proliferation during the early stage of muscle regeneration. PLoS One. 2012; 7(7):e41478. [PubMed: 22911796]

76. Anderson C, Catoe H, Werner R. MIR-206 regulates connexin43 expression during skeletal muscle development. Nucleic Acids Res. 2006; 34(20):5863-5871. [PubMed: 17062625]

77. Squecco R, Sassoli C, Nuti F, Martinesi M, Chellini F, Nosi D, Zecchi-Orlandini S, Francini F, Formigli L, Meaccis E. Sphingosine 1-phosphate induces myoblast differentiation through Cx43 protein expression: a role for a gap junction-dependent and -independent function. Mol Biol Cell. 2006; 17(11):4896-4910. [PubMed: 16957055]

78. Reinecke H, Minami E, Virag JI, Murry CE. Gene transfer of connexin43 into skeletal muscle. Hum Gene Ther. 2004; 15(7):627-636. [PubMed: 15242523]

79. Goljanek-Whysall K, Pais H, Rathjen T, Sweetman D, Dalmay T, Munsterberg A. Regulation of multiple target genes by miR-1 and miR-206 is pivotal for C2C12 myoblast differentiation. J Cell Sci. 2012; 125(Pt 15):3590-3600. [PubMed: 22595520]

80. Feng Y, Niu LL, Wei W, Zhang WY, Li XY, Cao JH, Zhao SH. A feedback circuit between miR-133 and the ERK1/2 pathway involving an exquisite mechanism for regulating myoblast proliferation and differentiation. Cell Death Dis. 2013; 4:e934. [PubMed: 24287695]

81. Liu N, Williams AH, Kim Y, McAnally J, Bezprozvannaya S, Sutherland LB, Richardson JA, Bassel-Duby R, Olson EN. An intragenic MEF2-dependent enhancer directs muscle-specific expression of microRNAs 1 and 133. Proc Natl Acad Sci U S A. 2007; 104(52):20844-20849. [PubMed: 18093911]

82. Wong CF, Tellam RL. MicroRNA-26a targets the histone methyltransferase Enhancer of Zeste homolog 2 during myogenesis. J Biol Chem. 2008; 283(15):9836-9843. [PubMed: 18281287]

83. Dey BK, Gagan J, Yan Z, Dutta A. miR-26a is required for skeletal muscle differentiation and regeneration in mice. Genes Dev. 2012; 26(19):2180-2191. [PubMed: 23028144]

84. Juan AH, Kumar RM, Marx JG, Young RA, Sartorelli V. Mir-214-dependent regulation of the polycomb protein Ezh2 in skeletal muscle and embryonic stem cells. Mol Cell. 2009; 36(1):61-74. [PubMed: 19818710] 
85. Liu J, Luo XJ, Xiong AW, Zhang ZD, Yue S, Zhu MS, Cheng SY. MicroRNA-214 promotes myogenic differentiation by facilitating exit from mitosis via down-regulation of proto-oncogene N-ras. J Biol Chem. 2010; 285(34):26599-26607. [PubMed: 20534588]

86. Shi K, Lu J, Zhao Y, Wang L, Li J, Qi B, Li H, Ma C. MicroRNA-214 suppresses osteogenic differentiation of C2C12 myoblast cells by targeting Osterix. Bone. 2013; 55(2):487-494. [PubMed: 23579289]

87. Sarkar S, Dey BK, Dutta A. MiR-322/424 and -503 are induced during muscle differentiation and promote cell cycle quiescence and differentiation by down-regulation of Cdc25A. Mol Biol Cell. 2010; 21(13):2138-2149. [PubMed: 20462953]

88. Wang H, Garzon R, Sun H, Ladner KJ, Singh R, Dahlman J, Cheng A, Hall BM, Qualman SJ, Chandler DS, Croce CM, Guttridge DC. NF-kappaB-YY1-miR-29 regulatory circuitry in skeletal myogenesis and rhabdomyosarcoma. Cancer Cell. 2008; 14(5):369-381. [PubMed: 18977326]

89. Wang XH, Hu Z, Klein JD, Zhang L, Fang F, Mitch WE. Decreased miR-29 suppresses myogenesis in CKD. J Am Soc Nephrol. 2011; 22(11):2068-2076. [PubMed: 21965375]

90. Wei W, He HB, Zhang WY, Zhang HX, Bai JB, Liu HZ, Cao JH, Chang KC, Li XY, Zhao SH. miR-29 targets Akt3 to reduce proliferation and facilitate differentiation of myoblasts in skeletal muscle development. Cell Death Dis. 2013; 4:e668. [PubMed: 23764849]

91. Zhou L, Wang L, Lu L, Jiang P, Sun H, Wang H. A novel target of microRNA-29, Ring1 and YY1binding protein (Rybp), negatively regulates skeletal myogenesis. J Biol Chem. 2012; 287(30): 25255-25265. [PubMed: 22661705]

92. Zhou L, Wang L, Lu L, Jiang P, Sun H, Wang H. Inhibition of miR-29 by TGF-beta-Smad3 signaling through dual mechanisms promotes transdifferentiation of mouse myoblasts into myofibroblasts. PLoS One. 2012; 7(3):e33766. [PubMed: 22438993]

93. Naguibneva I, Ameyar-Zazoua M, Polesskaya A, Ait-Si-Ali S, Groisman R, Souidi M, Cuvellier S, Harel-Bellan A. The microRNA miR-181 targets the homeobox protein Hox-A11 during mammalian myoblast differentiation. Nat Cell Biol. 2006; 8(3):278-284. [PubMed: 16489342]

94. Yamamoto M, Kuroiwa A. Hoxa-11 and Hoxa-13 are involved in repression of MyoD during limb muscle development. Dev Growth Differ. 2003; 45(5-6):485-498. [PubMed: 14706073]

95. Dey BK, Pfeifer K, Dutta A. The H19 long noncoding RNA gives rise to microRNAs miR-675-3p and miR-675-5p to promote skeletal muscle differentiation and regeneration. Genes Dev. 2014; 28(5):491-501. [PubMed: 24532688]

96. Snyder CM, Rice AL, Estrella NL, Held A, Kandarian SC, Naya FJ. MEF2A regulates the Gt12Dio3 microRNA mega-cluster to modulate WNT signaling in skeletal muscle regeneration. Development. 2013; 140(1):31-42. [PubMed: 23154418]

97. Chinchilla A, Lozano E, Daimi H, Esteban FJ, Crist C, Aranega AE, Franco D. MicroRNA profiling during mouse ventricular maturation: a role for miR-27 modulating Mef2c expression. Cardiovasc Res. 2011; 89(1):98-108. [PubMed: 20736237]

98. Crist CG, Montarras D, Pallafacchina G, Rocancourt D, Cumano A, Conway SJ, Buckingham M. Muscle stem cell behavior is modified by microRNA-27 regulation of Pax3 expression. Proc Natl Acad Sci U S A. 2009; 106(32):13383-13387. [PubMed: 19666532]

99. Wang L, Chen X, Zheng Y, Li F, Lu Z, Chen C, Liu J, Wang Y, Peng Y, Shen Z, Gao J, Zhu M, Chen H. MiR-23a inhibits myogenic differentiation through down regulation of fast myosin heavy chain isoforms. Exp Cell Res. 2012; 318(18):2324-2334. [PubMed: 22771720]

100. Marjoram RJ, Lessey EC, Burridge K. Regulation of RhoA Activity by Adhesion Molecules and Mechanotransduction. Curr Mol Med. 2014; 14(2):199-208. [PubMed: 24467208]

101. Shu L, Houghton PJ. The mTORC2 complex regulates terminal differentiation of $\mathrm{C} 2 \mathrm{C} 12$ myoblasts. Mol Cell Biol. 2009; 29(17):4691-4700. [PubMed: 19564418]

102. Charrasse S, Comunale F, Grumbach Y, Poulat F, Blangy A, Gauthier-Rouviere C. RhoA GTPase regulates M-cadherin activity and myoblast fusion. Mol Biol Cell. 2006; 17(2):749-759. [PubMed: 16291866]

103. Zhang J, Ying ZZ, Tang ZL, Long LQ, Li K. MicroRNA-148a promotes myogenic differentiation by targeting the ROCK1 gene. J Biol Chem. 2012; 287(25):21093-21101. [PubMed: 22547064] 
104. Koning M, Werker PM, van Luyn MJ, Krenning G, Harmsen MC. A global downregulation of microRNAs occurs in human quiescent satellite cells during myogenesis. Differentiation. 2012; 84(4):314-321. [PubMed: 23023067]

105. Bernstein E, Kim SY, Carmell MA, Murchison EP, Alcorn H, Li MZ, Mills AA, Elledge SJ, Anderson KV, Hannon GJ. Dicer is essential for mouse development. Nat Genet. 2003; 35(3): 215-217. [PubMed: 14528307]

106. O'Rourke JR, Georges SA, Seay HR, Tapscott SJ, McManus MT, Goldhamer DJ, Swanson MS, Harfe BD. Essential role for Dicer during skeletal muscle development. Dev Biol. 2007; 311(2): 359-368. [PubMed: 17936265]

107. Kwon C, Han Z, Olson EN, Srivastava D. MicroRNA1 influences cardiac differentiation in Drosophila and regulates Notch signaling. Proc Natl Acad Sci U S A. 2005; 102(52):1898618991. [PubMed: 16357195]

108. Deng Z, Chen JF, Wang DZ. Transgenic overexpression of miR-133a in skeletal muscle. BMC Musculoskelet Disord. 2011; 12:115. [PubMed: 21615921]

109. Chen Y, Melton DW, Gelfond JA, McManus LM, Shireman PK. MiR-351 transiently increases during muscle regeneration and promotes progenitor cell proliferation and survival upon differentiation. Physiol Genomics. 2012; 44(21):1042-1051. [PubMed: 22968638]

110. Ge Y, Sun Y, Chen J. IGF-II is regulated by microRNA-125b in skeletal myogenesis. J Cell Biol. 2011; 192(1):69-81. [PubMed: 21200031]

111. Nakasa T, Ishikawa M, Shi M, Shibuya H, Adachi N, Ochi M. Acceleration of muscle regeneration by local injection of muscle-specific microRNAs in rat skeletal muscle injury model. J Cell Mol Med. 2010; 14(10):2495-2505. [PubMed: 19754672]

112. Maciotta S, Meregalli M, Cassinelli L, Parolini D, Farini A, Fraro GD, Gandolfi F, Forcato M, Ferrari S, Gabellini D, Bicciato S, Cossu G, Torrente Y. Hmgb3 is regulated by microRNA-206 during muscle regeneration. PLoS One. 2012; 7(8):e43464. [PubMed: 22912879]

113. Nemeth MJ, Kirby MR, Bodine DM. Hmgb3 regulates the balance between hematopoietic stem cell self-renewal and differentiation. Proc Natl Acad Sci U S A. 2006; 103(37):13783-13788. [PubMed: 16945912]

114. Ge Y, Wu AL, Warnes C, Liu J, Zhang C, Kawasome H, Terada N, Boppart MD, Schoenherr CJ, Chen J. mTOR regulates skeletal muscle regeneration in vivo through kinase-dependent and kinase-independent mechanisms. Am J Physiol Cell Physiol. 2009; 297(6):C1434-C1444. [PubMed: 19794149]

115. Sun Y, Ge Y, Drnevich J, Zhao Y, Band M, Chen J. Mammalian target of rapamycin regulates miRNA-1 and follistatin in skeletal myogenesis. J Cell Biol. 2010; 189(7):1157-1169. [PubMed: 20566686]

116. Alexander MS, Casar JC, Motohashi N, Myers JA, Eisenberg I, Gonzalez RT, Estrella EA, Kang PB, Kawahara G, Kunkel LM. Regulation of DMD pathology by an ankyrin-encoded miRNA. Skelet Muscle. 2011; 1:27. [PubMed: 21824387]

117. Jia L, Li YF, Wu GF, Song ZY, Lu HZ, Song CC, Zhang QL, Zhu JY, Yang GS, Shi XE. MiRNA-199a-3p regulates C2C12 myoblast differentiation through IGF-1/AKT/mTOR signal pathway. Int J Mol Sci. 2014; 15(1):296-308. [PubMed: 24378853]

118. Caygill EE, Johnston LA. Temporal regulation of metamorphic processes in Drosophila by the let-7 and miR-125 heterochronic microRNAs. Curr Biol. 2008; 18(13):943-950. [PubMed: 18571409]

119. Sokol NS, Xu P, Jan YN, Ambros V. Drosophila let-7 microRNA is required for remodeling of the neuromusculature during metamorphosis. Genes Dev. 2008; 22(12):1591-1596. [PubMed: 18559475]

120. Simon DJ, Madison JM, Conery AL, Thompson-Peer KL, Soskis M, Ruvkun GB, Kaplan JM, Kim JK. The microRNA miR-1 regulates a MEF-2-dependent retrograde signal at neuromuscular junctions. Cell. 2008; 133(5):903-915. [PubMed: 18510933]

121. Sun K, Westholm JO, Tsurudome K, Hagen JW, Lu Y, Kohwi M, Betel D, Gao FB, Haghighi AP, Doe CQ, Lai EC. Neurophysiological defects and neuronal gene deregulation in Drosophila mir-124 mutants. PLoS Genet. 2012; 8(2):e1002515. [PubMed: 22347817] 
122. Tsurudome K, Tsang K, Liao EH, Ball R, Penney J, Yang JS, Elazzouzi F, He T, Chishti A, Lnenicka G, Lai EC, Haghighi AP. The Drosophila miR-310 cluster negatively regulates synaptic strength at the neuromuscular junction. Neuron. 2010; 68(5):879-893. [PubMed: 21145002]

123. Valdez G, Heyer MP, Feng G, Sanes JR. The role of muscle microRNAs in repairing the neuromuscular junction. PLoS One. 2014; 9(3):e93140. [PubMed: 24664281]

124. Loya CM, Lu CS, Van Vactor D, Fulga TA. Transgenic microRNA inhibition with spatiotemporal specificity in intact organisms. Nat Methods. 2009; 6(12):897-903. [PubMed: 19915559]

125. Loya CM, McNeill EM, Bao H, Zhang B, Van Vactor D. miR-8 controls synapse structure by repression of the actin regulator Enabled. Development. 2014; 141(9):1864-1874. [PubMed: 24718988]

126. Nesler KR, Sand RI, Symmes BA, Pradhan SJ, Boin NG, Laun AE, Barbee SA. The miRNA pathway controls rapid changes in activity-dependent synaptic structure at the Drosophila melanogaster neuromuscular junction. PLoS One. 2013; 8(7):e68385. [PubMed: 23844193]

127. Miura P, Amirouche A, Clow C, Belanger G, Jasmin BJ. Brain-derived neurotrophic factor expression is repressed during myogenic differentiation by miR-206. J Neurochem. 2012; 120(2): 230-238. [PubMed: 22081998]

128. McCarthy JJ, Esser KA. MicroRNA-1 and microRNA-133a expression are decreased during skeletal muscle hypertrophy. J Appl Physiol (1985). 2007; 102(1):306-313. [PubMed: 17008435]

129. Drummond MJ, McCarthy JJ, Fry CS, Esser KA, Rasmussen BB. Aging differentially affects human skeletal muscle microRNA expression at rest and after an anabolic stimulus of resistance exercise and essential amino acids. Am J Physiol Endocrinol Metab. 2008; 295(6):E1333-E1340. [PubMed: 18827171]

130. Elia L, Contu R, Quintavalle M, Varrone F, Chimenti C, Russo MA, Cimino V, De Marinis L, Frustaci A, Catalucci D, Condorelli G. Reciprocal regulation of microRNA-1 and insulin-like growth factor-1 signal transduction cascade in cardiac and skeletal muscle in physiological and pathological conditions. Circulation. 2009; 120(23):2377-2385. [PubMed: 19933931]

131. Gagan J, Dey BK, Layer R, Yan Z, Dutta A. MicroRNA-378 targets the myogenic repressor MyoR during myoblast differentiation. J Biol Chem. 2011; 286(22):19431-19438. [PubMed: 21471220]

132. Safdar A, Abadi A, Akhtar M, Hettinga BP, Tarnopolsky MA. miRNA in the regulation of skeletal muscle adaptation to acute endurance exercise in C57B1/6J male mice. PLoS One. 2009; 4(5):e5610. [PubMed: 19440340]

133. Aoi W, Naito Y, Mizushima K, Takanami Y, Kawai Y, Ichikawa H, Yoshikawa T. The microRNA miR-696 regulates PGC-1 \{alpha\} in mouse skeletal muscle in response to physical activity. Am J Physiol Endocrinol Metab. 2010; 298(4):E799-E806. [PubMed: 20086200]

134. Yamamoto H, Morino K, Nishio Y, Ugi S, Yoshizaki T, Kashiwagi A, Maegawa H. MicroRNA-494 regulates mitochondrial biogenesis in skeletal muscle through mitochondrial transcription factor A and Forkhead box j3. Am J Physiol Endocrinol Metab. 2012; 303(12):E1419-R1427. [PubMed: 23047984]

135. Fernandes T, Magalhaes FC, Roque FR, Phillips MI, Oliveira EM. Exercise training prevents the microvascular rarefaction in hypertension balancing angiogenic and apoptotic factors: role of microRNAs-16, -21, and -126. Hypertension. 2012; 59(2):513-520. [PubMed: 22215713]

136. Sun CY, She XM, Qin Y, Chu ZB, Chen L, Ai LS, Zhang L, Hu Y. miR-15a and miR-16 affect the angiogenesis of multiple myeloma by targeting VEGF. Carcinogenesis. 2013; 34(2):426-435. [PubMed: 23104180]

137. Olfert IM, Howlett RA, Wagner PD, Breen EC. Myocyte vascular endothelial growth factor is required for exercise-induced skeletal muscle angiogenesis. Am J Physiol Regul Integr Comp Physiol. 2010; 299(4):R1059-R1067. [PubMed: 20686173]

138. Nielsen S, Scheele C, Yfanti C, Akerstrom T, Nielsen AR, Pedersen BK, Laye MJ. Muscle specific microRNAs are regulated by endurance exercise in human skeletal muscle. J Physiol. 2010; 588(Pt 20):4029-4037. [PubMed: 20724368]

139. Russell AP, Lamon S, Boon H, Wada S, Guller I, Brown EL, Chibalin AV, Zierath JR, Snow RJ, Stepto N, Wadley GD, Akimoto T. Regulation of miRNAs in human skeletal muscle following 
acute endurance exercise and short-term endurance training. J Physiol. 2013; 591(Pt 18):46374653. [PubMed: 23798494]

140. Keller P, Vollaard NB, Gustafsson T, Gallagher IJ, Sundberg CJ, Rankinen T, Britton SL, Bouchard C, Koch LG, Timmons JA. A transcriptional map of the impact of endurance exercise training on skeletal muscle phenotype. J Appl Physiol (1985). 2011; 110(1):46-59. [PubMed: 20930125]

141. Radom-Aizik S, Zaldivar F Jr, Oliver S, Galassetti P, Cooper DM. Evidence for microRNA involvement in exercise-associated neutrophil gene expression changes. J Appl Physiol (1985). 2010; 109(1):252-261. [PubMed: 20110541]

142. Radom-Aizik S, Zaldivar F Jr, Leu SY, Adams GR, Oliver S, Cooper DM. Effects of exercise on microRNA expression in young males peripheral blood mononuclear cells. Clin Transl Sci. 2012; 5(1):32-38. [PubMed: 22376254]

143. Radom-Aizik S, Zaldivar F, Haddad F, Cooper DM. Impact of brief exercise on peripheral blood NK cell gene and microRNA expression in young adults. J Appl Physiol (1985). 2013; 114(5): 628-636. [PubMed: 23288554]

144. Baggish AL, Hale A, Weiner RB, Lewis GD, Systrom D, Wang F, Wang TJ, Chan SY. Dynamic regulation of circulating microRNA during acute exhaustive exercise and sustained aerobic exercise training. J Physiol. 2011; 589(Pt 16):3983-3994. [PubMed: 21690193]

145. Aoi W, Ichikawa H, Mune K, Tanimura Y, Mizushima K, Naito Y, Yoshikawa T. Muscle-enriched microRNA miR-486 decreases in circulation in response to exercise in young men. Front Physiol. 2013; 4:80. [PubMed: 23596423]

146. Sawada S, Kon M, Wada S, Ushida T, Suzuki K, Akimoto T. Profiling of circulating microRNAs after a bout of acute resistance exercise in humans. PLoS One. 2013; 8(7):e70823. [PubMed: 23923026]

147. Banzet S, Chennaoui M, Girard O, Racinais S, Drogou C, Chalabi H, Koulmann N. Changes in circulating microRNAs levels with exercise modality. J Appl Physiol (1985). 2013; 115(9):12371244. [PubMed: 23950168]

148. Uhlemann M, Mobius-Winkler S, Fikenzer S, Adam J, Redlich M, Mohlenkamp S, Hilberg T, Schuler GC, Adams V. Circulating microRNA-126 increases after different forms of endurance exercise in healthy adults. Eur J Prev Cardiol. 2012

149. Bye A, Rosjo H, Aspenes ST, Condorelli G, Omland T, Wisloff U. Circulating microRNAs and aerobic fitness--the HUNT-Study. PLoS One. 2013; 8(2):e57496. [PubMed: 23469005]

150. Izzotti A. Genomic biomarkers and clinical outcomes of physical activity. Ann N Y Acad Sci. 2011; 1229:103-114. [PubMed: 21793845]

151. Mooren FC, Viereck J, Kruger K, Thum T. Circulating micrornas as potential biomarkers of aerobic exercise capacity. Am J Physiol Heart Circ Physiol. 2014; 306(4):H557-H563. [PubMed: 24363306]

152. Nielsen S, Akerstrom T, Rinnov A, Yfanti C, Scheele C, Pedersen BK, Laye MJ. The miRNA Plasma Signature in Response to Acute Aerobic Exercise and Endurance Training. PLoS One. 2014; 9(2):e87308. [PubMed: 24586268]

153. Wang XH. MicroRNA in myogenesis and muscle atrophy. Curr Opin Clin Nutr Metab Care. 2013; 16(3):258-266. [PubMed: 23449000]

154. Emery AE. The muscular dystrophies. Lancet. 2002; 359(9307):687-695. [PubMed: 11879882]

155. Eisenberg I, Eran A, Nishino I, Moggio M, Lamperti C, Amato AA, Lidov HG, Kang PB, North KN, Mitrani-Rosenbaum S, Flanigan KM, Neely LA, Whitney D, Beggs AH, Kohane IS, Kunkel LM. Distinctive patterns of microRNA expression in primary muscular disorders. Proc Natl Acad Sci U S A. 2007; 104(43):17016-17021. [PubMed: 17942673]

156. Alexander MS, Kawahara G, Motohashi N, Casar JC, Eisenberg I, Myers JA, Gasperini MJ, Estrella EA, Kho AT, Mitsuhashi S, Shapiro F, Kang PB, Kunkel LM. MicroRNA-199a is induced in dystrophic muscle and affects WNT signaling, cell proliferation, and myogenic differentiation. Cell Death Differ. 2013; 20(9):1194-1208. [PubMed: 23764775]

157. Ardite E, Perdiguero E, Vidal B, Gutarra S, Serrano AL, Munoz-Canoves P. PAI-1-regulated miR-21 defines a novel age-associated fibrogenic pathway in muscular dystrophy. J Cell Biol. 2012; 196(1):163-175. [PubMed: 22213800] 
158. Greco S, De Simone M, Colussi C, Zaccagnini G, Fasanaro P, Pescatori M, Cardani R, Perbellini R, Isaia E, Sale P, Meola G, Capogrossi MC, Gaetano C, Martelli F. Common micro-RNA signature in skeletal muscle damage and regeneration induced by Duchenne muscular dystrophy and acute ischemia. Faseb J. 2009; 23(10):3335-3346. [PubMed: 19528256]

159. McCarthy JJ, Esser KA, Andrade FH. MicroRNA-206 is overexpressed in the diaphragm but not the hindlimb muscle of mdx mouse. Am J Physiol Cell Physiol. 2007; 293(1):C451-C457. [PubMed: 17459947]

160. Yuasa K, Hagiwara Y, Ando M, Nakamura A, Takeda S, Hijikata T. MicroRNA-206 is highly expressed in newly formed muscle fibers: implications regarding potential for muscle regeneration and maturation in muscular dystrophy. Cell Struct Funct. 2008; 33(2):163-169. [PubMed: 18827405]

161. Cacchiarelli D, Incitti T, Martone J, Cesana M, Cazzella V, Santini T, Sthandier O, Bozzoni I. miR-31 modulates dystrophin expression: new implications for Duchenne muscular dystrophy therapy. EMBO Rep. 2011; 12(2):136-141. [PubMed: 21212803]

162. Perbellini R, Greco S, Sarra-Ferraris G, Cardani R, Capogrossi MC, Meola G, Martelli F. Dysregulation and cellular mislocalization of specific miRNAs in myotonic dystrophy type 1 . Neuromuscul Disord. 2011; 21(2):81-88. [PubMed: 21169019]

163. Gambardella S, Rinaldi F, Lepore SM, Viola A, Loro E, Angelini C, Vergani L, Novelli G, Botta A. Overexpression of microRNA-206 in the skeletal muscle from myotonic dystrophy type 1 patients. J Transl Med. 2010; 8:48. [PubMed: 20487562]

164. Fernandez-Costa JM, Garcia-Lopez A, Zuniga S, Fernandez-Pedrosa V, Felipo-Benavent A, Mata M, Jaka O, Aiastui A, Hernandez-Torres F, Aguado B, Perez-Alonso M, Vilchez JJ, Lopez de Munain A, Artero RD. Expanded CTG repeats trigger miRNA alterations in Drosophila that are conserved in myotonic dystrophy type 1 patients. Hum Mol Genet. 2013; 22(4):704-716. [PubMed: 23139243]

165. Greco S, Perfetti A, Fasanaro P, Cardani R, Capogrossi MC, Meola G, Martelli F. Deregulated microRNAs in myotonic dystrophy type 2. PLoS One. 2012; 7(6):e39732. [PubMed: 22768114]

166. Dmitriev P, Lipinski M, Vassetzky YS. Pearls in the junk: dissecting the molecular pathogenesis of facioscapulohumeral muscular dystrophy. Neuromuscul Disord. 2009; 19(1):17-20. [PubMed: 18974002]

167. Dmitriev P, Stankevicins L, Ansseau E, Petrov A, Barat A, Dessen P, Robert T, Turki A, Lazar V, Labourer E, Belayew A, Carnac G, Laoudj-Chenivesse D, Lipinski M, Vassetzky YS. Defective regulation of microRNA target genes in myoblasts from facioscapulohumeral dystrophy patients. J Biol Chem. 2013; 288(49):34989-35002. [PubMed: 24145033]

168. Harafuji N, Schneiderat P, Walter MC, Chen YW. miR-411 is up-regulated in FSHD myoblasts and suppresses myogenic factors. Orphanet J Rare Dis. 2013; 8:55. [PubMed: 23561550]

169. Winokur ST, Barrett K, Martin JH, Forrester JR, Simon M, Tawil R, Chung SA, Masny PS, Figlewicz DA. Facioscapulohumeral muscular dystrophy (FSHD) myoblasts demonstrate increased susceptibility to oxidative stress. Neuromuscul Disord. 2003; 13(4):322-333. [PubMed: 12868502]

170. Geng LN, Yao Z, Snider L, Fong AP, Cech JN, Young JM, van der Maarel SM, Ruzzo WL, Gentleman RC, Tawil R, Tapscott SJ. DUX4 activates germline genes, retroelements, and immune mediators: implications for facioscapulohumeral dystrophy. Dev Cell. 2012; 22(1):3851. [PubMed: 22209328]

171. Briani C, Doria A, Sarzi-Puttini P, Dalakas MC. Update on idiopathic inflammatory myopathies. Autoimmunity. 2006; 39(3):161-170. [PubMed: 16769649]

172. Georgantas RW, Streicher K, Greenberg SA, Greenlees L, Zhu W, Brohawn P, Higgs BW, Czapiga M, Morehouse C, Amato A, Richman L, Jallal B, Yao Y, Ranade K. Inhibition of myogenic MicroRNAs-1, 133, and 206 by inflammatory cytokines links inflammation and muscle degeneration in adult inflammatory myopathies. Arthritis Rheum. 2013

173. Kim E, Cook-Mills J, Morgan G, Sredni ST, Pachman LM. Increased expression of vascular cell adhesion molecule 1 in muscle biopsy samples from juvenile dermatomyositis patients with short duration of untreated disease is regulated by miR-126. Arthritis Rheum. 2012; 64(11):38093817. [PubMed: 22740338] 
174. Ishtiaq M, Campos-Melo D, Volkening K, Strong MJ. Analysis of Novel NEFL mRNA Targeting microRNAs in Amyotrophic Lateral Sclerosis. PLoS One. 2014; 9(1):e85653. [PubMed: 24454911]

175. Russell AP, Wada S, Vergani L, Hock MB, Lamon S, Leger B, Ushida T, Cartoni R, Wadley GD, Hespel P, Kralli A, Soraru G, Angelini C, Akimoto T. Disruption of skeletal muscle mitochondrial network genes and miRNAs in amyotrophic lateral sclerosis. Neurobiol Dis. 2012; 49C:107-117. [PubMed: 22975021]

176. Bruneteau G, Simonet T, Bauche S, Mandjee N, Malfatti E, Girard E, Tanguy ML, Behin A, Khiami F, Sariali E, Hell-Remy C, Salachas F, Pradat PF, Fournier E, Lacomblez L, Koenig J, Romero NB, Fontaine B, Meininger V, Schaeffer L, Hantai D. Muscle histone deacetylase 4 upregulation in amyotrophic lateral sclerosis: potential role in reinnervation ability and disease progression. Brain. 2013; 136(Pt 8):2359-2368. [PubMed: 23824486]

177. D'Souza DM, Al-Sajee D, Hawke TJ. Diabetic myopathy: impact of diabetes mellitus on skeletal muscle progenitor cells. Front Physiol. 2013; 4:379. [PubMed: 24391596]

178. McClelland AD, Kantharidis P. microRNA in the development of diabetic complications. Clin Sci (Lond). 2014; 126(2):95-110. [PubMed: 24059587]

179. Hudson MB, Woodworth-Hobbs ME, Zheng B, Rahnert JA, Blount MA, Gooch JL, Searles CD, Price SR. miR-23a is decreased during muscle atrophy by a mechanism that includes calcineurin signaling and exosome-mediated export. Am J Physiol Cell Physiol. 2013

180. Huang B, Qin W, Zhao B, Shi Y, Yao C, Li J, Xiao H, Jin Y. MicroRNA expression profiling in diabetic GK rat model. Acta Biochim Biophys Sin (Shanghai). 2009; 41(6):472-477. [PubMed: 19499150]

181. Jiang LQ, Franck N, Egan B, Sjogren RJ, Katayama M, Duque-Guimaraes D, Arner P, Zierath JR, Krook A. Autocrine role of interleukin-13 on skeletal muscle glucose metabolism in type 2 diabetic patients involves microRNA let-7. Am J Physiol Endocrinol Metab. 2013; 305(11):E1359-E1366. [PubMed: 24105413]

182. Karolina DS, Armugam A, Tavintharan S, Wong MT, Lim SC, Sum CF, Jeyaseelan K. MicroRNA 144 impairs insulin signaling by inhibiting the expression of insulin receptor substrate 1 in type 2 diabetes mellitus. PLoS One. 2011; 6(8):e22839. [PubMed: 21829658]

183. Agarwal P, Srivastava R, Srivastava AK, Ali S, Datta M. miR-135a targets IRS2 and regulates insulin signaling and glucose uptake in the diabetic gastrocnemius skeletal muscle. Biochim Biophys Acta. 2013; 1832(8):1294-1303. [PubMed: 23579070]

184. Zhang Y, Yang L, Gao YF, Fan ZM, Cai XY, Liu MY, Guo XR, Gao CL, Xia ZK. MicroRNA-106b induces mitochondrial dysfunction and insulin resistance in C2C12 myotubes by targeting mitofusin-2. Mol Cell Endocrinol. 2013; 381(1-2):230-240. [PubMed: 23954742]

185. Gallagher IJ, Scheele C, Keller P, Nielsen AR, Remenyi J, Fischer CP, Roder K, Babraj J, Wahlestedt C, Hutvagner G, Pedersen BK, Timmons JA. Integration of microRNA changes in vivo identifies novel molecular features of muscle insulin resistance in type 2 diabetes. Genome Med. 2010; 2(2):9. [PubMed: 20353613]

186. Chen GQ, Lian WJ, Wang GM, Wang S, Yang YQ, Zhao ZW. Altered microRNA expression in skeletal muscle results from high-fat diet-induced insulin resistance in mice. Mol Med Rep. 2012; 5(5):1362-1368. [PubMed: 22395471]

187. Bach D, Naon D, Pich S, Soriano FX, Vega N, Rieusset J, Laville M, Guillet C, Boirie Y, Wallberg-Henriksson H, Manco M, Calvani M, Castagneto M, Palacin M, Mingrone G, Zierath JR, Vidal H, Zorzano A. Expression of Mfn2, the Charcot-Marie-Tooth neuropathy type 2A gene, in human skeletal muscle: effects of type 2 diabetes, obesity, weight loss, and the regulatory role of tumor necrosis factor alpha and interleukin-6. Diabetes. 2005; 54(9):2685-2693. [PubMed: 16123358]

188. Mak RH, Cheung WW. MicroRNAs: a new therapeutic frontier for muscle wasting in chronic kidney disease. Kidney Int. 2012; 82(4):373-374. [PubMed: 22846810]

189. Xu J, Li R, Workeneh B, Dong Y, Wang X, Hu Z. Transcription factor FoxO1, the dominant mediator of muscle wasting in chronic kidney disease, is inhibited by microRNA-486. Kidney Int. 2012; 82(4):401-411. [PubMed: 22475820] 
190. Lewis A, Riddoch-Contreras J, Natanek SA, Donaldson A, Man WD, Moxham J, Hopkinson NS, Polkey MI, Kemp PR. Downregulation of the serum response factor/miR-1 axis in the quadriceps of patients with COPD. Thorax. 2012; 67(1):26-34. [PubMed: 21998125]

191. Donaldson A, Natanek SA, Lewis A, Man WD, Hopkinson NS, Polkey MI, Kemp PR. Increased skeletal muscle-specific microRNA in the blood of patients with COPD. Thorax. 2013; 68(12): 1140-1149. [PubMed: 23814167]

192. Hasselgren PO. Glucocorticoids and muscle catabolism. Curr Opin Clin Nutr Metab Care. 1999; 2(3):201-205. [PubMed: 10456248]

193. Kukreti H, Amuthavalli K, Harikumar A, Sathiyamoorthy S, Feng PZ, Anantharaj R, Tan SL, Lokireddy S, Bonala S, Sriram S, McFarlane C, Kambadur R, Sharma M. Muscle-specific microRNA1 (miR1) targets heat shock protein 70 (HSP70) during dexamethasone-mediated atrophy. J Biol Chem. 2013; 288(9):6663-6678. [PubMed: 23297411]

194. Ling N, Gu J, Lei Z, Li M, Zhao J, Zhang HT, Li X. microRNA-155 regulates cell proliferation and invasion by targeting FOXO3a in glioma. Oncol Rep. 2013; 30 2111-82013.

195. Shen H, Liu T, Fu L, Zhao S, Fan B, Cao J, Li X. Identification of microRNAs involved in dexamethasone-induced muscle atrophy. Mol Cell Biochem. 2013; 381(1-2):105-113. [PubMed: 23716137]

196. Allen DL, Loh AS. Posttranscriptional mechanisms involving microRNA-27a and b contribute to fast-specific and glucocorticoid-mediated myostatin expression in skeletal muscle. Am J Physiol Cell Physiol. 2011; 300(1):C124-C137. [PubMed: 20980549]

197. Hudson MB, Woodworth-Hobbs ME, Zheng B, Rahnert JA, Blount MA, Gooch JL, Searles CD, Price SR. miR-23a is decreased during muscle atrophy by a mechanism that includes calcineurin signaling and exosome-mediated export. Am J Physiol Cell Physiol. 2013

198. Wada S, Kato Y, Okutsu M, Miyaki S, Suzuki K, Yan Z, Schiaffino S, Asahara H, Ushida T, Akimoto T. Translational suppression of atrophic regulators by microRNA-23a integrates resistance to skeletal muscle atrophy. J Biol Chem. 2011; 286(44):38456-38465. [PubMed: 21926429]

199. Allen DL, Bandstra ER, Harrison BC, Thorng S, Stodieck LS, Kostenuik PJ, Morony S, Lacey DL, Hammond TG, Leinwand LL, Argraves WS, Bateman TA, Barth JL. Effects of spaceflight on murine skeletal muscle gene expression. J Appl Physiol (1985). 2009; 106(2):582-595. [PubMed: 19074574]

200. McCarthy JJ, Esser KA, Peterson CA, Dupont-Versteegden EE. Evidence of MyomiR network regulation of beta-myosin heavy chain gene expression during skeletal muscle atrophy. Physiol Genomics. 2009; 39(3):219-226. [PubMed: 19690046]

201. Rezen T, Kovanda A, Eiken O, Mekjavic IB, Rogelj B. Expression changes in human skeletal muscle miRNAs following 10 days of bed rest in young healthy males. Acta Physiol (Oxf). 2014

202. Ringholm S, Bienso RS, Kiilerich K, Guadalupe-Grau A, Aachmann-Andersen NJ, Saltin B, Plomgaard P, Lundby C, Wojtaszewski JF, Calbet JA, Pilegaard H. Bed rest reduces metabolic protein content and abolishes exercise-induced mRNA responses in human skeletal muscle. Am J Physiol Endocrinol Metab. 2011; 301(4):E649-E658. [PubMed: 21750272]

203. McCarthy JJ. The MyomiR network in skeletal muscle plasticity. Exerc Sport Sci Rev. 2011; 39(3):150-154. [PubMed: 21467943]

204. Bell ML, Buvoli M, Leinwand LA. Uncoupling of expression of an intronic microRNA and its myosin host gene by exon skipping. Mol Cell Biol. 2010; 30(8):1937-1945. [PubMed: 20154144]

205. Haddad F, Adams GR, Bodell PW, Baldwin KM. Isometric resistance exercise fails to counteract skeletal muscle atrophy processes during the initial stages of unloading. J Appl Physiol. 2006; 100(2):433-441. [PubMed: 16239603]

206. Hamrick MW, Herberg S, Arounleut P, He HZ, Shiver A, Qi RQ, Zhou L, Isales CM, Mi QS. The adipokine leptin increases skeletal muscle mass and significantly alters skeletal muscle miRNA expression profile in aged mice. Biochem Biophys Res Commun. 2010; 400(3):379-383. [PubMed: 20800581]

207. Mercken EM, Majounie E, Ding J, Guo R, Kim J, Bernier M, Mattison J, Cookson MR, Gorospe M, de Cabo R, Abdelmohsen K. Age-associated miRNA alterations in skeletal muscle from 
rhesus monkeys reversed by caloric restriction. Aging (Albany NY). 2013; 5(9):692-703. [PubMed: 24036467]

208. Nomura T, Ueyama T, Ashihara E, Tateishi K, Asada S, Nakajima N, Isodono K, Takahashi T, Matsubara H, Oh H. Skeletal muscle-derived progenitors capable of differentiating into cardiomyocytes proliferate through myostatin-independent TGF-beta family signaling. Biochem Biophys Res Commun. 2008; 365(4):863-869. [PubMed: 18047832]

209. Cardinali B, Castellani L, Fasanaro P, Basso A, Alema S, Martelli F, Falcone G. Microrna-221 and microrna-222 modulate differentiation and maturation of skeletal muscle cells. PLoS One. 2009; 4(10):e7607. [PubMed: 19859555]

210. Drummond MJ, McCarthy JJ, Sinha M, Spratt HM, Volpi E, Esser KA, Rasmussen BB. Aging and MicroRNA Expression in Human Skeletal Muscle: A Microarray and Bioinformatics Analysis. Physiol Genomics. 2011

211. Mueller M, Breil FA, Lurman G, Klossner S, Fluck M, Billeter R, Dapp C, Hoppeler H. Different molecular and structural adaptations with eccentric and conventional strength training in elderly men and women. Gerontology. 2011; 57(6):528-538. [PubMed: 21311168]

212. De Giovanni C, Landuzzi L, Nicoletti G, Lollini PL, Nanni P. Molecular and cellular biology of rhabdomyosarcoma. Future Oncol. 2009; 5(9):1449-1475. [PubMed: 19903072]

213. Novak J, Vinklarek J, Bienertova-Vasku J, Slaby O. MicroRNAs involved in skeletal muscle development and their roles in rhabdomyosarcoma pathogenesis. Pediatr Blood Cancer. 2013; 60(11):1739-1746. [PubMed: 23813576]

214. Yan D, Dong Xda E, Chen X, Wang L, Lu C, Wang J, Qu J, Tu L. MicroRNA-1/206 targets c-Met and inhibits rhabdomyosarcoma development. J Biol Chem. 2009; 284(43):29596-29604. [PubMed: 19710019]

215. Rao PK, Missiaglia E, Shields L, Hyde G, Yuan B, Shepherd CJ, Shipley J, Lodish HF. Distinct roles for miR-1 and miR-133a in the proliferation and differentiation of rhabdomyosarcoma cells. Faseb J. 2010; 24(9):3427-3437. [PubMed: 20466878]

216. Missiaglia E, Shepherd CJ, Patel S, Thway K, Pierron G, Pritchard-Jones K, Renard M, Sciot R, Rao P, Oberlin O, Delattre O, Shipley J. MicroRNA-206 expression levels correlate with clinical behaviour of rhabdomyosarcomas. Br J Cancer. 2010; 102(12):1769-1777. [PubMed: 20502458]

217. Diao Y, Guo X, Jiang L, Wang G, Zhang C, Wan J, Jin Y, Wu Z. miR-203, a Tumor Suppressor Frequently Down-regulated by Promoter Hypermethylation in Rhabdomyosarcoma. J Biol Chem. 2014; 289(1):529-539. [PubMed: 24247238]

218. Ciarapica R, Russo G, Verginelli F, Raimondi L, Donfrancesco A, Rota R, Giordano A. Deregulated expression of miR-26a and Ezh2 in rhabdomyosarcoma. Cell Cycle. 2009; 8(1):172175. [PubMed: 19106613]

219. Sarver AL, Li L, Subramanian S. MicroRNA miR-183 functions as an oncogene by targeting the transcription factor EGR1 and promoting tumor cell migration. Cancer Res. 2010; 70(23):95709580. [PubMed: 21118966]

220. Hu J, Kong M, Ye Y, Hong S, Cheng L, Jiang L. Serum miR-206 and other muscle-specific microRNAs as noninvasive biomarkers for Duchenne muscular dystrophy. J Neurochem. 2014

\section{Abbreviations}

$\begin{array}{ll}\text { miRNA } & \text { microRNA } \\ \text { TGF- } \beta & \text { Transforming growth factor- beta } \\ \text { PAX3 } & \text { paired-box } 3 \\ \text { PAX7 } & \text { Paired-box 7 } \\ \text { MYOD } & \text { myogenic differentiation } \\ \text { MYF5 } & \text { Myogenic factor 5 }\end{array}$




$\begin{array}{ll}\text { MRF4 } & \text { Myogenic regulatory factor } 4 \\ \text { Mef2 } & \text { Myocyte enhancing factor } \\ \text { SRF } & \text { serum response factor } \\ \text { HDAC4 } & \text { Histone deacetylase 4 } \\ \text { EZH2 } & \text { Enhancer of zeste homolog 2 } \\ \text { YY1 } & \text { Ying yang 1 } \\ \text { mTOR } & \text { mechanical target of rapamycin } \\ \text { IGF } & \text { Insulin-like growth factor } \\ \text { PTEN } & \text { phosphatase and tensin homolog } \\ \text { CKD } & \text { chronic kidney disease } \\ \text { RMS } & \text { rhabdomyosarcoma } \\ \text { DMD } & \text { Duchenne muscular dystrophy } \\ \text { FSHD } & \text { Facioscapulohumeral muscular dystrophy } \\ \text { ALS } & \text { Amyotrphic lateral sclerosis } \\ \text { Dex } & \text { Dexamethasone } \\ \text { NMJ } & \text { neuromuscular junction }\end{array}$




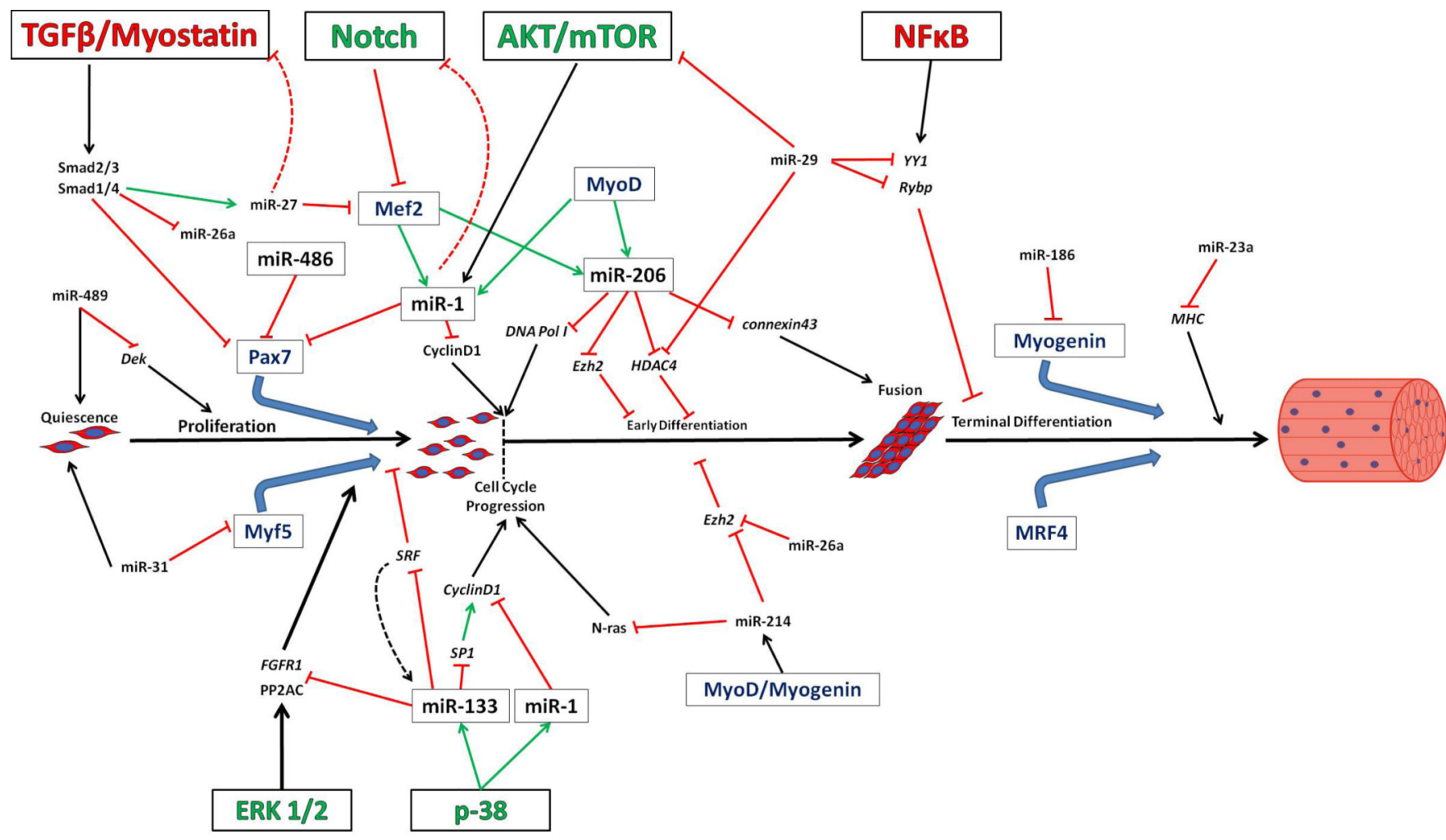

Figure 1.

The microRNA network that is involved in regulating myogenesis. Major myogenic regulatory factors (MFRs) and muscle-enriched miRNAs are indicated by a box. Signaling pathways that promote myogenesis (either proliferation or differentiation) are denoted by green text. Signaling pathways that inhibit myogenesis are denoted by red text. Green arrows $(\leftarrow)$ indicate direct upregulation of a gene or miRNA. Blunt red arrows $(\perp)$ indicate direct down-regulation of a gene or miRNA. Black arrows indicate general stimulation of a biological process or pathway. 

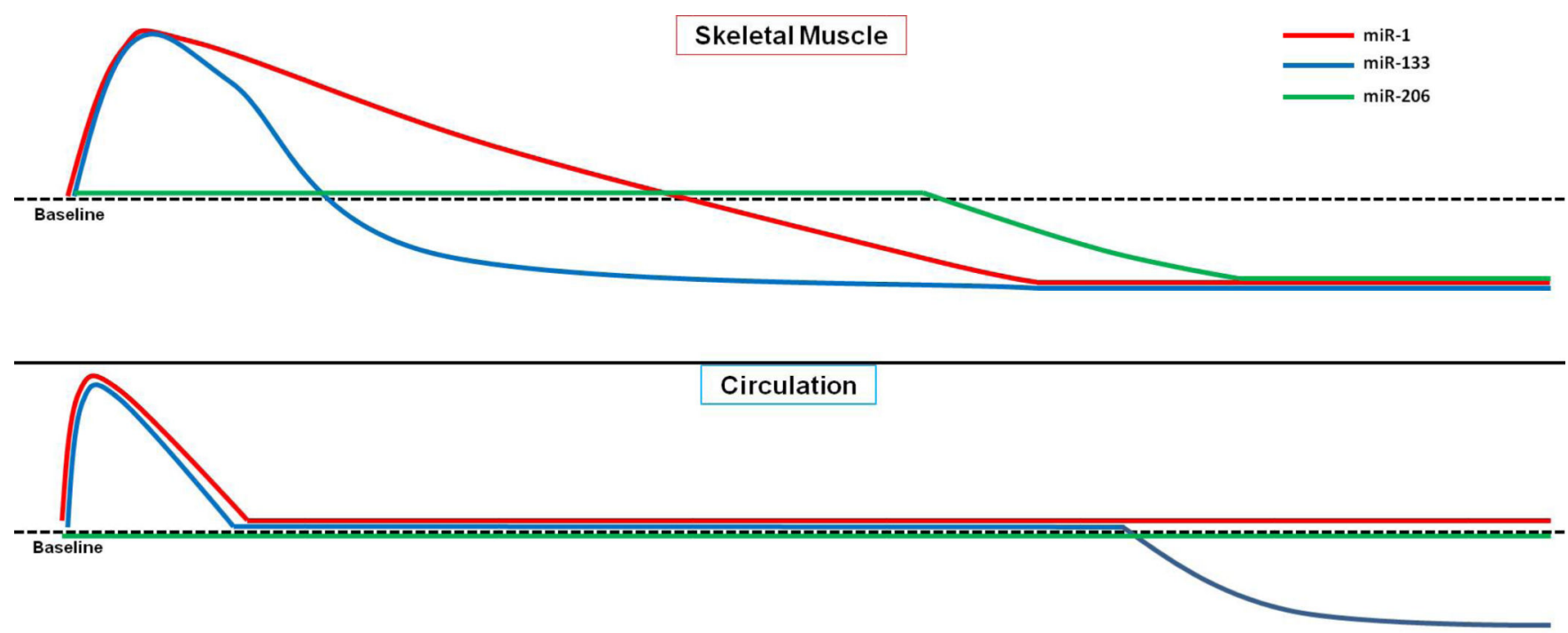

\begin{tabular}{cccc}
\hline Acute & Acute Training & Short Term Training $(\sim 6$ & Chronic Training \\
Bout & $(\sim 10$ Davs $)$ & Weeks $)$ & $(>12$ Weeks $)$
\end{tabular}

Figure 2.

Temporal changes of microRNA levels in either skeletal muscle or circulation in response to aerobic exercise. The model is based on published data examining the temporal response of the myomiRs in human participants. Generally, miR-1 and -133 demonstrate an increase in both skeletal muscle and the circulation in response to an acute endurance exercise bout, however the increase in circulation may only occur following intense bouts. Conversely, following training these miRNAs, along with miR-206, appear to be down-regulated. In the circulation, training results in minimal change in these miRNAs, however miR-133 may become down-regulated. 


\section{Table 1}

MicroRNAs controlling myogenic progenitor cell fate

\begin{tabular}{|c|c|c|c|c|}
\hline Cell State & miRNA & Targets & Biological Role of miRNA & References \\
\hline \multirow[t]{2}{*}{ Quiescence } & $\operatorname{miR}-489$ & Dek & $\begin{array}{l}\text { Regulation of the proliferation of daughter cells primed for differentiation } \\
\text { following } \\
\text { asymmetrical division }\end{array}$ & 67 \\
\hline & $\operatorname{miR}-31$ & Myf5 & Suppression of Myf5 protein levels prior to signals for differentiation & 68 \\
\hline \multirow[t]{4}{*}{ Proliferation } & $\operatorname{miR}-133 \mathrm{a}$ & Srf & $\begin{array}{l}\text { Promotes proliferation by repressing SRF, a transcription factor involved } \\
\text { in regulating the } \\
\text { expression for differentiation genes }\end{array}$ & 52 \\
\hline & \multirow[t]{2}{*}{$\operatorname{miR}-27 \mathrm{a}$} & Myostatin & Promotes myogenesis by relieving the negative regulation of myostatin & 69 \\
\hline & & $\operatorname{Pax} 3$ & Promotes proper migration of myogenic progenitor cells & 98 \\
\hline & $\operatorname{miR}-27 b$ & $\operatorname{Mef} 2 c$ & $\begin{array}{l}\text { Inhibits differentiation and promotes proliferation by suppressing Mef2c } \\
\text { levels thereby not } \\
\text { allowing association with myogenic regulatory factors }\end{array}$ & 97 \\
\hline \multirow[t]{20}{*}{ Differentiation } & \multirow{5}{*}{$\operatorname{miR}-1$} & $\operatorname{Pax} 7$ & $\begin{array}{l}\text { Promotes differentiation by downregulating Pax } 7 \text { and the genes under its } \\
\text { control }\end{array}$ & $72-73$ \\
\hline & & connexin43 & $\begin{array}{l}\text { Inhibits the formation of gap junctions, which need to be absent from } \\
\text { mature myotubes }\end{array}$ & 76 \\
\hline & & CyclinD1 & Promotes cell cycle arrest & 75 \\
\hline & & Hdac4 & $\begin{array}{l}\text { Relieves the repressive effects of HDAC on chromatin associated with } \\
\text { myogenic genes }\end{array}$ & 52 \\
\hline & & Notch3 & Promotes differentiation & 64 \\
\hline & \multirow{3}{*}{$\operatorname{miR}-133$} & $S p 1$ & $\begin{array}{l}\text { Promotes cell cycle arrest through downregulation of SP1 target, } \\
\text { CyclinD1 }\end{array}$ & 75 \\
\hline & & Fgfr1 & Inhibits proliferation through suppression of ERK1/2 signaling & 80 \\
\hline & & $P p 2 a c$ & & \\
\hline & \multirow{5}{*}{ miR-206 } & $\operatorname{Pax} 7$ & $\begin{array}{l}\text { Promotes differentiation by downregulating Pax } 7 \text { and the genes under its } \\
\text { control }\end{array}$ & 73 \\
\hline & & $\begin{array}{l}\text { Subunits of DNA } \\
\text { Pola }\end{array}$ & Cell cycle Arrest & 51 \\
\hline & & connexin43 & $\begin{array}{l}\text { Inhibits the formation of gap junctions, which need to be absent from } \\
\text { mature myotubes }\end{array}$ & 76 \\
\hline & & Notch 3 & $\begin{array}{l}\text { Promotes differentiation by downregulating Notch signaling, which } \\
\text { normally acts to inhibit } \\
\text { premature differentiation }\end{array}$ & 64 \\
\hline & & $H m g b 3$ & $\begin{array}{l}\text { Promotes myogenesis by relieving inhibitory effects of } \mathrm{Hmgb3} \text {, a } \\
\text { chromatin binding protein, } \\
\text { which acts to inhibits expression of myogenic genes }\end{array}$ & 112 \\
\hline & \multirow[b]{2}{*}{$\operatorname{miR}-486$} & $\operatorname{Pax} 7$ & $\begin{array}{l}\text { Promotes differentiation by downregulating Pax } 7 \text { and the genes under its } \\
\text { control }\end{array}$ & 73 \\
\hline & & Pten & $\begin{array}{l}\text { Promotes activation of mTOR signaling by relieving inhibitory effects of } \\
\text { PTEN on the } \\
\text { pathway }\end{array}$ & 116 \\
\hline & \multirow{2}{*}{ MiR-26a } & Ezh2 & Relieves the repressive effects of Polycomb complex on myogenic genes & 82 \\
\hline & & Smad1/4 & Inhibits TGF- $\beta$ signaling to promote myogenesis & 83 \\
\hline & \multirow{2}{*}{ miR-214 } & Ezh2 & Relieves the repressive effects of Polycomb complex on myogenic genes & 84 \\
\hline & & $N$-Ras & Promotes cell cycle arrest & 85 \\
\hline & MiR-503 & $C d c 25 A$ & Promotes cell cycle arrest & 87 \\
\hline
\end{tabular}

Front Biosci (Landmark Ed). Author manuscript; available in PMC 2016 May 03. 


\begin{tabular}{|c|c|c|c|c|}
\hline Cell State & miRNA & Targets & Biological Role of miRNA & References \\
\hline & \multirow{4}{*}{$\begin{array}{l}\mathrm{miR}-29 \\
\mathrm{~b} / \mathrm{c}\end{array}$} & Yy1 & Relieves inhibitory effects of $\mathrm{NF \kappa B}$ on myogenesis & 88 \\
\hline & & Rybp & & 91 \\
\hline & & Hdac4 & $\begin{array}{l}\text { Relieves the repressive effects of HDAC on chromatin associated with } \\
\text { myogenic genes }\end{array}$ & 74 \\
\hline & & Akt3 & Inhibits AKT/mTOR signaling & 90 \\
\hline & \multirow{2}{*}{$\operatorname{miR}_{3 \mathrm{p}}-675-$} & Smad1/5/6 & Inhibits TGF- $\beta$ signaling & \multirow{4}{*}{95} \\
\hline & & Cdc6 & Promotes cell cycle arrest and differentiation & \\
\hline & \multirow{2}{*}{$\begin{array}{l}\operatorname{miR}-675- \\
5 p\end{array}$} & Smad1/5/6 & Inhibits TGF- $\beta$ signaling to promote myogenesis & \\
\hline & & $C d c 6$ & Promotes cell cycle arrest and differentiation & \\
\hline & \multirow{3}{*}{$\begin{array}{l}\operatorname{miR}-199 \mathrm{a}- \\
3 \mathrm{p}\end{array}$} & Igf-1 & Inhibition of AKT/mTOR Signaling & \multirow{3}{*}{117} \\
\hline & & Pik3r1 & & \\
\hline & & mTOR & & \\
\hline & $\operatorname{miR}-155$ & $\operatorname{Mef} 2 c$ & $\begin{array}{l}\text { Inhibits differentiation and promotes proliferation by suppressing Mef2c } \\
\text { levels thereby not } \\
\text { allowing its association with myogenic regulatory factors }\end{array}$ & 66 \\
\hline & miR-181 & Hox-A11 & Promotes upregulation of MyoD which is inhibited by Hox-A11 & 93 \\
\hline & miR-23a & Myh 1,2 and 4 & $\begin{array}{l}\text { Suppresses expression of contractile proteins required for the terminally } \\
\text { differentiated } \\
\text { phenotype }\end{array}$ & 99 \\
\hline & miR-148a & Rock1 & Cytoskeleton stability & 103 \\
\hline
\end{tabular}


Table 2

MicroRNA dysregulation associated with muscle disorders

\begin{tabular}{|c|c|c|c|c|}
\hline Category & Family & Disease/disorder & miRNA expression & Reference \\
\hline \multirow{10}{*}{$\begin{array}{l}\text { Primary } \\
\text { muscular } \\
\text { disorder }\end{array}$} & \multirow{5}{*}{ Dystrophy } & $\begin{array}{l}\text { Duchenne } \\
\text { muscular } \\
\text { dystrophy (DMD) }\end{array}$ & $\begin{array}{l}\uparrow \text { of } 39 \text { miRNAs and } \downarrow \text { of } 23 \text { miRNAs; } \uparrow \text { miR-199a-5p; } \downarrow \\
\text { miR- } 486 ; \uparrow \\
\text { of } 8 \text { miRNAs (including miR-206 and miR-31), } \downarrow \text { of } 3 \\
\text { miRNAs } \\
\text { (including miR-1); } \uparrow \text { miR-1, miR-206 and miR-133 in } \\
\text { serum of } \\
\text { DMD children; } \uparrow \text { miR-21 }\end{array}$ & $\begin{array}{l}155 ; 156 ; 116 ; 158 \\
220 ; 157\end{array}$ \\
\hline & & $\begin{array}{l}\text { Myotonic } \\
\text { dystrophy (type1 } \\
\text { and 2) }\end{array}$ & $\begin{array}{l}\uparrow \text { miR-206 in most of the DM } 1^{3} \text { patients, no effect on } \\
\text { miR-1; } \uparrow \text { miR- } \\
1 \text { and miR-335, } \downarrow \text { miR-29b, miR-29c and miR-33 in DM1 } \\
\text { patients; } \downarrow \\
\text { miR-1, miR-7 and miR-10a in DM1 patients; } \uparrow \text { of } 12 \\
\text { miRNAs } \\
\text { (including miR-133b), } \downarrow \text { of } 8 \text { miRNAs (including 133a) in } \\
\text { DM2 } 4 \\
\text { patients }\end{array}$ & $163 ; 162 ; 164 ; 165$ \\
\hline & & $\begin{array}{l}\text { Becker muscular } \\
\text { dystrophy (BMD) }\end{array}$ & $\uparrow \mathrm{miR}-146 \mathrm{~b}$ and miR-221 & 155 \\
\hline & & $\begin{array}{l}\text { Facioscapulohume } \\
\text { ral muscular } \\
\text { dystrophy (FSHD) }\end{array}$ & $\begin{array}{l}\uparrow \text { of } 62 \text { miRNAs; } \uparrow \text { of } 21 \text { miRNAs (including miR- } 1, \\
\text { miR-133a, } \\
\text { miR-133b and miR-206), } \downarrow 8 \text { miRNAs in primary } \\
\text { myoblasts of } \\
\text { FSHD patients; } \uparrow \text { of } 2 \text { miRNAs, } \downarrow \text { of } 6 \text { miRNAs in primary } \\
\text { myoblasts of FSHD patients }\end{array}$ & $155 ; 167 ; 168$ \\
\hline & & $\begin{array}{l}\text { Limb-girdle } \mathrm{MD} \\
\text { type } 2 \mathrm{~A} \text { and } 2 \mathrm{~B}\end{array}$ & $\begin{array}{l}\uparrow \text { of } 88(2 \mathrm{~A}) \text { and } 87 \text { (2B) miRNAs, } \downarrow \text { of } 4(2 \mathrm{~A}) \text { and } 5 \text { (2B) } \\
\text { miRNAs }\end{array}$ & 155 \\
\hline & \multirow{5}{*}{ Myopathy } & Miyoshi myopathy & $\uparrow$ of 68 miRNAs, $\downarrow$ of 5 miRNAs & 155 \\
\hline & & $\begin{array}{l}\text { Nemaline } \\
\text { myopathy }\end{array}$ & $\uparrow^{1}$ of 130 miRNAs, $\downarrow^{2}$ of 13 miRNAs & 155 \\
\hline & & Polymyositis & $\begin{array}{l}\uparrow \text { of } 37 \text { miRNAs, } \downarrow \text { miR-30a-3p; } \downarrow \text { miR-1, miR133a and } \\
\text { miR-133b }\end{array}$ & $155 ; 172$ \\
\hline & & Dermatomyositis & $\begin{array}{l}\uparrow \text { of } 35 \text { miRNAs, } \downarrow \text { of } 2 \text { miRNAs; } \downarrow \text { miR-1, miR133a, } \\
\text { miR-133b and } \\
\text { miR-206; } \downarrow \text { miR-126 in juvenile DM patients with short } \\
\text { duration of } \\
\text { untreated disease }\end{array}$ & $155 ; 172 ; 173$ \\
\hline & & $\begin{array}{l}\text { Inclusion body } \\
\text { myositis }\end{array}$ & $\begin{array}{l}\uparrow \text { of } 20 \text { miRNAs, } \downarrow \text { of } 2 \text { miRNAs; } \downarrow \text { miR- } 1, \text { miR133a and } \\
\text { miR-133b }\end{array}$ & $155 ; 172$ \\
\hline \multirow{5}{*}{$\begin{array}{l}\text { Secondary } \\
\text { muscular } \\
\text { disorder }\end{array}$} & $\begin{array}{l}\text { Neurodegenerative } \\
\text { disease }\end{array}$ & $\begin{array}{l}\text { Amyotrophic } \\
\text { lateral sceloris }\end{array}$ & $\uparrow \mathrm{miR}-206 ; \uparrow \mathrm{miR}-23 \mathrm{a}$, miR-29b, miR-206 and miR-455 & $176 ; 175$ \\
\hline & \multirow{3}{*}{ Disease-related } & $\mathrm{CKD}^{5}$ & $\begin{array}{l}\downarrow \text { miR- } 486 \text { in CKD mice; } \uparrow \text { of } 5 \text { miRNAs, } \downarrow \text { of } 7 \text { miRNAs } \\
\text { (including } \\
\text { miR-29a and miR-29b) in CKD mice }\end{array}$ & $189 ; 89$ \\
\hline & & Diabetes mellitus & $\begin{array}{l}\downarrow \text { miR-23a in diabetic rats; } \uparrow \text { Let-7a and Let-7d in T2DM } 6 \\
\text { patients; } \uparrow \\
\text { of } 10 \text { miRNAs, } \downarrow \text { of } 21 \text { miRNAs in diabetic mice; } \uparrow \text { of } 2 \\
\text { miRNAs, } \downarrow \\
\text { of } 7 \text { miRNAs in diabetic rats; } \downarrow \text { miR-133a and miR-206 in } \\
\text { T2DM } \\
\text { patients }\end{array}$ & $\begin{array}{l}179 ; 181 ; 183 \\
180 ; 185\end{array}$ \\
\hline & & $\mathrm{COPD}^{7}$ & $\begin{array}{l}\downarrow \text { miR-1; } \uparrow \text { miR-1, miR-133, miR-206 and miR-499 in } \\
\text { plasma of } \\
\text { COPD patients }\end{array}$ & $190 ; 191$ \\
\hline & Disuse-related & Bedrest & $\begin{array}{l}\downarrow \text { of } 13 \text { miRNAs (including miR-206 and miR-23a), } \uparrow \text { of } 2 \\
\text { miRNAs; }\end{array}$ & $201 ; 202$ \\
\hline
\end{tabular}

Front Biosci (Landmark Ed). Author manuscript; available in PMC 2016 May 03. 


\begin{tabular}{|c|c|c|c|c|c|}
\hline \multirow{7}{*}{ 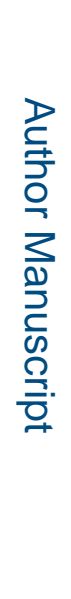 } & Category & Family & Disease/disorder & miRNA expression & Reference \\
\hline & & & & $\downarrow$ miR-1 and miR-133a & \\
\hline & & & Immobilization & $\uparrow \mathrm{miR}-680, \mathrm{miR}-696, \mathrm{miR}-705$ and miR-762 in mice & 133 \\
\hline & & & Spaceflight & $\downarrow \mathrm{miR}-206$ in mice & 199 \\
\hline & & & $\begin{array}{l}\text { Hindlimb } \\
\text { suspension }\end{array}$ & $\downarrow$ miR-107, miR-221, miR-499 and miR-208b in rats & 200 \\
\hline & Sarcopenia & & & $\begin{array}{l}\text { No } \downarrow \text { miR- } 1 \text { in response to resistance exercise combined } \\
\text { with }{ }_{\text {EAA }} \\
\text { ingestion; } \uparrow \text { Let-b and Let-e; } \downarrow \text { of } 36 \text { miRNAs, } \uparrow \text { of } 21 \\
\text { miRNAs in } \\
\text { mice; } \downarrow \text { of } 30 \text { miRNAs, } \uparrow \text { of } 5 \text { miRNAs in rhesus monkey s }\end{array}$ & $129 ; 210 ; 206 ; 207$ \\
\hline & Rhabdomy & ar coma (RMS) & & $\begin{array}{l}\text { Suppression of miR- } 1 \text { and miR-206; } \downarrow \text { miR-29b and miR-1; } \\
\downarrow \text { miR-1, } \\
\text { miR-206, miR-133a and miR-133b; } \uparrow \text { miR-301, } \downarrow \text { miR-27a } \\
\text { and miR- } \\
26 \text {; } \uparrow \text { miR-183; } \downarrow \text { miR-203 }\end{array}$ & $\begin{array}{l}214 ; 88 ; 216 ; 218 \\
219 ; 217\end{array}$ \\
\hline
\end{tabular}

$1_{\uparrow, \text { upregulation; }}$

${ }^{2} \downarrow$, down-regulation;

3 DM1, myotonic dystrophy type 1 ;

${ }^{4}$ DM2, myotonic dystrophy type 2 ;

${ }^{5} \mathrm{CKD}$, chronic kidney disease;

$\sigma_{\text {T2DM, type 2-diabetes mellitus; }}$

${ }^{7}$ COPD, chronic obstructive pulmonary disease;

${ }^{8}$ EAA, essential amino acids. 